\title{
Article \\ A Low-Power High-Efficiency Adaptive Energy Harvesting Circuit for Broadband Piezoelectric Vibration Energy Harvester
}

\author{
Aicheng Zou ${ }^{1,2 * *}$, Zhong Liu ${ }^{2}$ and Xingguo Han ${ }^{2}$ \\ 1 State Key Laboratory of Mechanics and Control of Mechanical Structures, Nanjing University of Aeronautics \\ and Astronautics, Nanjing 210016, China \\ 2 School of Mechanical Engineering, Guilin University of Aerospace Technology, Guilin 541004, China; \\ liuzhong678@163.com (Z.L.); hanxingguo@guat.edu.cn (X.H.) \\ * Correspondence: zouaicheng@guat.edu.cn
}

check for updates

Citation: Zou, A.; Liu, Z.; Han, X. A Low-Power High-Efficiency Adaptive Energy Harvesting Circuit for Broadband Piezoelectric Vibration Energy Harvester. Actuators 2021, 10, 327. https://doi.org/10.3390/ act10120327

Academic Editor: Kenji Uchino

Received: 9 November 2021

Accepted: 8 December 2021

Published: 10 December 2021

Publisher's Note: MDPI stays neutral with regard to jurisdictional claims in published maps and institutional affiliations.

Copyright: (c) 2021 by the authors. Licensee MDPI, Basel, Switzerland. This article is an open access article distributed under the terms and conditions of the Creative Commons Attribution (CC BY) license (https:// creativecommons.org/licenses/by/ $4.0 /)$.

\begin{abstract}
Existing piezoelectric vibration energy harvesting circuits require auxiliary power for the switch control module and are difficult to adapt to broadband piezoelectric vibration energy harvesters. This paper proposes a self-powered and low-power enhanced double synchronized switch harvesting (EDSSH) circuit. The proposed circuit consists of a low-power follow-up switch control circuit, reverse feedback blocking-up circuit, synchronous electric charge extraction circuit and buck-boost circuit. The EDSSH circuit can automatically adapt to the sinusoidal voltage signal with the frequency of 1 to $312.5 \mathrm{~Hz}$ that is output by the piezoelectric vibration energy harvester. The switch control circuit of the EDSSH circuit works intermittently for a very short time near the power extreme point and consumes a low amount of electric energy. The reverse feedback blocking-up circuit of the EDSSH circuit can keep the transmission efficiency at the optimal value. By using a charging capacitor of $1 \mathrm{mF}$, the charging efficiency of the proposed EDSSH circuit is 1.51 times that of the DSSH circuit.
\end{abstract}

Keywords: piezoelectric; vibration energy harvester; low-power; high-efficiency; circuit

\section{Introduction}

The self-powered wireless sensor which can automatically obtain electric energy from ambient vibration has great application prospects in the field of structural health detection [1-3]. It is important to develop an efficient self-powered system which can automatically convert environmental vibration energy into electric energy for the application of wireless sensors. Piezoelectric smart structures have been widely studied in the field of ambient vibration energy harvesting because of their sensitivity to vibration, high energy density $[4,5]$ and high output voltage $[6,7]$. The research on piezoelectric vibration energy harvesting systems mainly includes three aspects: the modeling theory and method, the mechanical structure optimization design and the energy harvesting interface circuit.

Researchers have deeply investigated the modeling theory and methods of piezoelectric vibrators. Some analytical models are already available in the literature. Erturk and Inman [8,9] established an analytical distributed parameter model for cantilevered piezoelectric energy harvesters. Liao and Sodano $[10,11]$ developed a theoretical model of a piezoelectric energy harvesting system to predict the power around a single vibration mode based on the Rayleigh-Ritz approach. Fakharian and Salmani [12] researched a lumped parameter model for an exponentially tapered piezoelectric beam in transverse vibration. Kärki [13], Baishya [14], Wang [15], Sriramdas [16] and Rammohan [17] studied a lumped-parameter transducer model for piezoelectric and ferroelectric polymers. Elvin $[18,19]$ proposed a general equivalent circuit model for piezoelectric generators and a coupled finite element-circuit simulation model for analyzing a piezoelectric energy generator. Roundy [20] established a distributed parameter model for improving power 
output for vibration-based energy scavengers. Yang and Tang [21] established an equivalent circuit modeling of piezoelectric energy harvesters. Wang [22], Zhang [23], Ko [24] and Saleem [25] investigated modeling and parameter identification for equivalent circuit modeling of piezoelectric energy harvesters with theoretical analysis. Noël [26], He [27], Wang [28], Xie [29] and Billings [30] put forward a method of modeling and parameter identification for the circuit model of a nonlinear piezoelectric vibrator.

Several methods have been proposed by researchers to improve the energy conversion efficiency and expand the band of the operation frequency of VEHs. One of the approaches is frequency tuning, such as mechanical tuning [31-35], circuit tuning and magnetic tuning [36-39]. This strategy allows VEHs to adjust their resonant frequency according to the environmental vibration frequency. However, this increases the complexity or consume extra energy of the VEHs. For instance, Eichhorn [31] proposed a piezoelectric energy harvesting structure of a cantilever beam with additional mechanical mass, which changes the resonant frequency of the structure by applying pressure or tensile force to the cantilever beam. Fan [39] designed a vibration energy harvester that composed of a piezoelectric harvester, stopper and magnet. The system can tune the vibration energy harvester to a lower working frequency range by changing the gap between mass and magnets, so as to improve the efficiency of energy collection. Another approach is to use multi-modal energy capture technology with different resonant frequencies, including generator arrays [40-43] and coupled vibration [44-49]. Although coupled vibration is easy to achieve, the maximum output power of the VEH is consequently reduced. Nabavi [40] proposed a piezoelectric MEMS harvester with symmetrical and double clamping structure, which has multi-mode and nonlinear characteristics and effectively broadens the working bandwidth. Hu [44] proposed a broadband multi mass and multi spring piezoelectric vibration energy harvester based on a folded asymmetric gap cantilever beam, which can make each stage of pure bending form multiple resonance modes. The working frequency band of the structure is widened effectively. Recently, nonlinear vibration energy harvesting approaches, for instance, nonlinear magnetic coupling [50-56] and piecewise-linear structure [57-60], have attracted the interest of researchers. Although energy conversion efficiency of the unit volume material is decreased, the operation frequency band of the VEH could be widened.

There are special requirements for piezoelectric energy harvesters (PEHs) and their electric energy harvesting circuits due to the wide range of vibration frequency and large load range of actual working environment. Therefore, a low-power high-efficiency adaptive energy harvesting circuit which can match the PEH with wide operation frequency band and load range is the key to the practical application of the piezoelectric system.

The standard energy harvesting (SEH) [61,62] interface circuit was first reported as a power harvesting circuit of PEHs for its simple structures and needless of external control module, but the energy harvesting efficiency is low and obviously affected by load. Lefeuvre [63] proposed a two-stage interface circuit of the down-to-step voltage converter, which has low power and can charge a $4.8 \mathrm{~V}$ rechargeable battery efficiently. Garbuio and Guyomar [64-66] investigated the synchronized switch harvesting on inductor (SSHI) technique for vibration control of piezoelectric structures, which adds synchronous switching damping at both ends of piezoelectric elements to improve the efficiency of energy harvesting. The SSHI scheme uses an LC resonant circuit for capacitor charging to reduce energy loss. Liang and Badel $[67,68]$ proposed a synchronous switch damping technology by adding series inductors in the circuit, in which the synchronous switch is used to quickly flip the piezoelectric voltage and improve the energy conversion efficiency. Shu, Ramadass, Lefeurve and Lallart [69-72] developed the Seris-SSHI (S-SSHI) and the parallel-SSHI (P-SSHI) technologies further, but the circuit scheme requires impedance matching to achieve maximum power transmission and can only match the load in a narrow range. Lefeuvre [73], Gasnier [74] and Dini [75] studied the SSHI technology and proposed synchronous electric charge extraction (SECE) technology. The energy harvesting efficiency of the SECE scheme is independent of the load, and the range of matching loads 
is wide for the use of the LC resonant circuit to transfer the power of the PEH to the inductor and then to the load through the DC-DC converter in the SECE scheme.

Recently, researchers proposed a class of double synchronized switch harvesting (DSSH) [76-78] circuits as shown in Figure 1 by optimizing the control of switches of SECE to make the circuit more efficient. Wang [79] analyzed a self-powered, ultra-low-power control circuit for weak coupling and heavy load. Wu [80] used two resonant rings to flip the capacitor voltage in each half cycle to improve the power harvesting efficiency of an SSHI circuit. Din [81] designed an energy harvesting circuit based on MOS devices to reduce power consumption. Chen [82] reported a fast self-starting and low-power management circuit for a micro piezoelectric energy harvester. Lallart [83] studied a nonlinear technology and self-powered circuit to harvest energy from PEHs under no-load conditions efficiently. The main shortcomings of the DSSH circuit are the complexity of the switch control, the need for an additional switch control circuit and auxiliary power supply, and the low conversion efficiency due to the inaccurate switch time control. To the best of our knowledge, existing solutions have either low energy harvesting efficiency such as the SEH circuit [61,62], are unable to sufficiently match loads such as P-SSHI and S-SSHI circuits [64-66,73-75] or are excessively complicated and require auxiliary power for the switch control circuit [76-78].

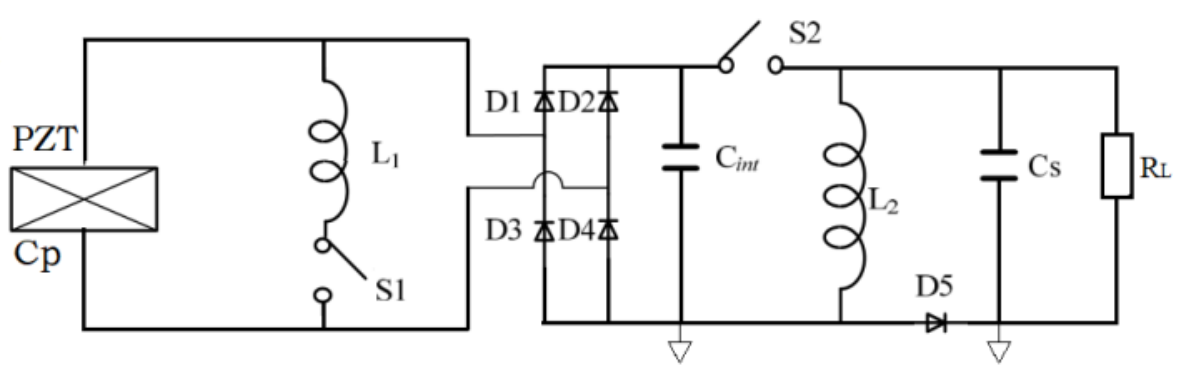

Figure 1. Schematic diagram of the DSSH circuit.

This paper proposes a low-power high-efficiency adaptive double synchronized switch harvesting circuit for broadband PEHs based on DSSH called an enhanced double synchronized switch harvesting (EDSSH) circuit. The schematic diagram is shown in Figure 2. The EDSSH circuit has four advantages. First, compared with DSSH, the EDSSH circuit simplifies the switching control circuit, reduces the power consumption of the switching control circuit and does not need a special auxiliary power supply. Moreover, in order to reduce the power consumption, the switch control circuit is in the sleep state most of the time and starts automatically only for a short time near the power extreme point. Secondly, the EDSSH circuit adds a power reverse feedback blocking-up circuit (RFBC) into DSSH to keep the energy harvesting efficiency optimal and avoid the problem of unstable energy harvesting efficiency of the DSSH circuit. Thirdly, the EDSSH circuit inherits the power extreme value tracking point technology of DSSH, which has stronger energy harvesting efficiency than SEH and SSHI circuits. Lastly, it can automatically adapt to input voltage signals with a wide frequency range.

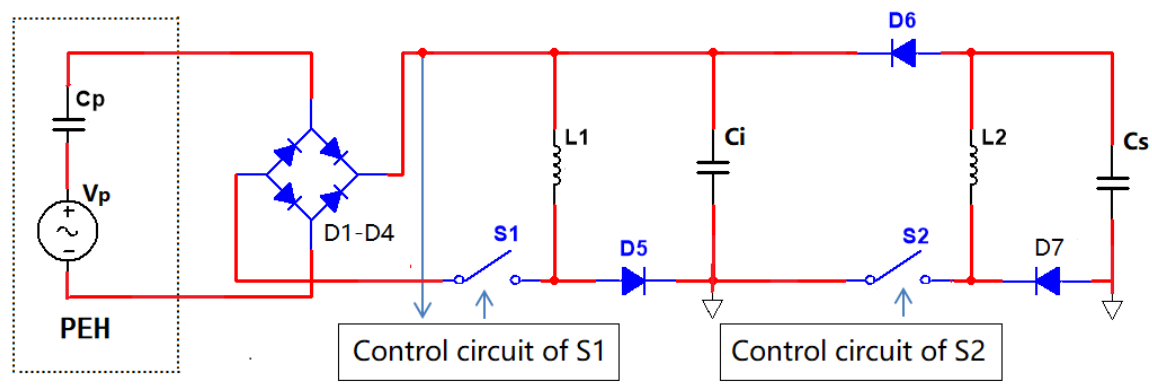

Figure 2. Schematic diagram of EDSSH circuit. 


\section{The Proposed EDSSH Circuit}

\subsection{Structure of EDSSH Circuit}

The proposed EDSSH circuit is shown in Figure 2. The simulation circuit according to the schematic diagram of the EDSSH circuit is shown in Figure 3. The circuit includes a PEH, a rectifier bridge, an energy transfer circuit composed of $S_{1}-L_{1}-D_{5}-C_{i}-S_{2}-D_{6}$, a buck-boost circuit, the control circuit of switch $S_{1}$ and the control circuit of switch $S_{2}$. The PEH part is represented by an $A C$ voltage source $V_{P}(12.26 \mathrm{~V}, 50 \mathrm{~Hz})$ and a capacitance $C_{P}(62.36 \mathrm{nF})$.

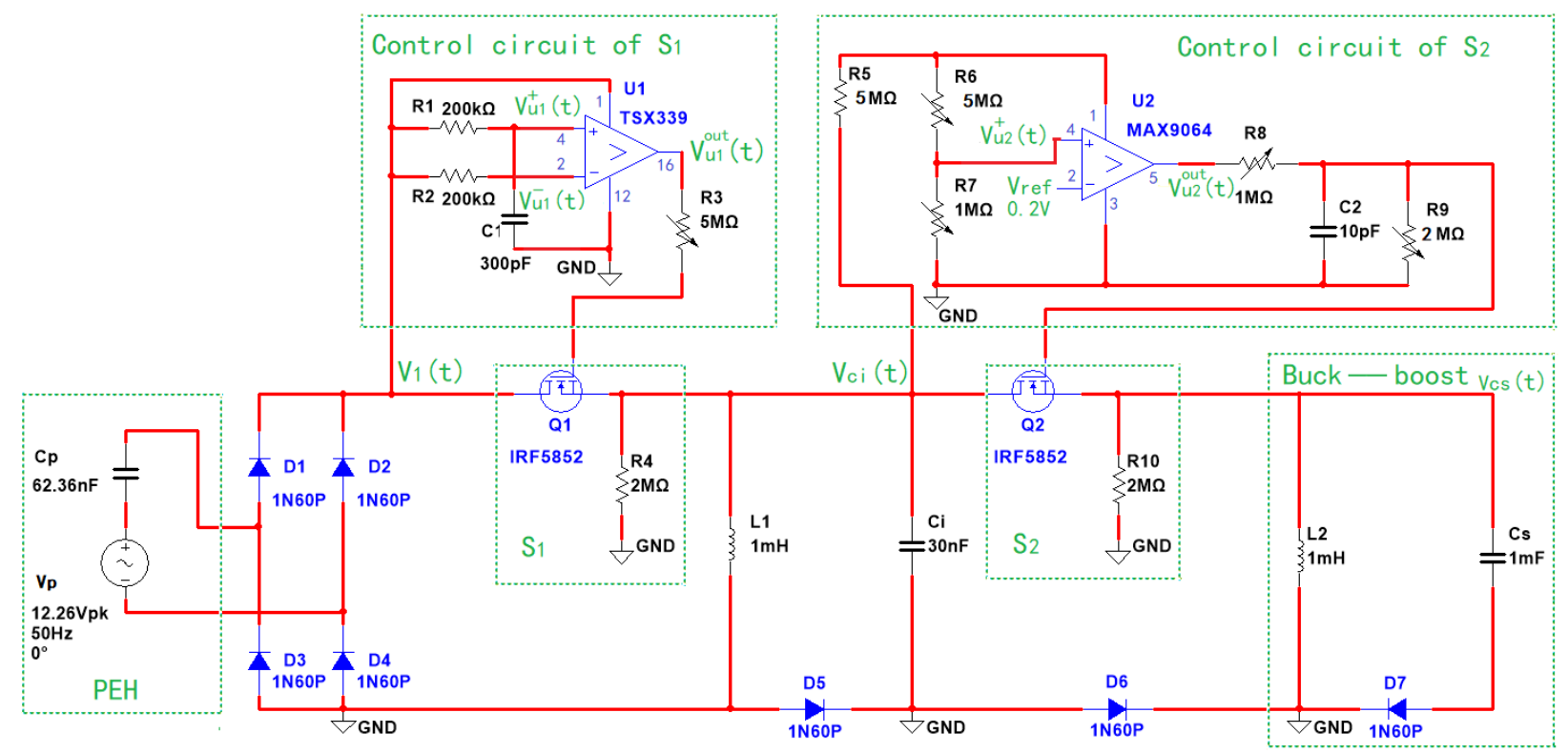

Figure 3. Simulation circuit of the EDSSH circuit.

The EDSSH circuit consists of four working circuits:

(1) The first circuit loop is composed of the capacitor $C_{P}$, rectifier bridge $D_{1}-D_{4}$, inductor $\mathrm{L}_{1}$, ultra-low on-resistance MOSFET $\mathrm{Q}_{1}$ (representative switch $\mathrm{S}_{1}$ ) and control circuit of $S_{1}$. This circuit is used to harvest the electric energy generated by the PEH. Compared with DSSH, the EDSSH circuit has three improvements. First, the EDSSH circuit simplifies the switching control circuit and uses a simple structure and low-power IC, a comparator TSX339, three resistors and one capacitor. The control circuit of $S_{1}$ is composed of the micro-power quad CMOS voltage comparator TSX339 and its peripheral circuit. The no-inverting input terminal of TSX339 is connected to $V_{1}(t)$ through the RC signal delay circuit (delay time $T_{C}=R_{1} * C_{1}$ ). The inverting input terminal of TSX339 is connected to $V_{1}(t)$ through the current limiting resistor $\mathrm{R}_{2}$. The terminal $V_{c c}$ is connected to $V_{1}(t)$ directly. The ground terminal of TSX339 is grounded. The output terminal of TSX339 is connected to the gate terminal of $\mathrm{Q}_{1}$ through an adjustable resistor $\mathrm{R}_{3}$. Secondly, other passive components are also low power consumption. The rectifier bridge $\mathrm{D}_{1}-\mathrm{D}_{4}$ is composed of four ultra-low-power IN60P diodes with forward voltage of $0.24 \mathrm{~V}$, reverse voltage of $40 \mathrm{~V}$ and maximum forward current of $50 \mathrm{~mA}$. The controlled switch $\mathrm{S}_{1}$ is represented by N-channel MOSFET IRF5852 with ultra-low static drain-to-source on-resistance $\left(R_{D S(o n)}\right)$ of $0.09 \Omega$, switch frequency exceeding $10^{8} / \mathrm{s}$ and minimum drain-to-source breakdown voltage $\left(V_{B R(D S S)}\right)$ of $20 \mathrm{~V}$. Thirdly, the control circuit of $S_{1}$ with low power and low-cold-start threshold does not need additional power supply but is supplied by the output voltage $V_{1}(t)$ of the rectifier bridge. The control circuit of $S_{1}$ can automatically control $S_{1}$ turn on for a brief time when the voltage of $V_{1}(t)$ reaches the extreme value and consumes very little power. That is, TSX339 compares the voltage of the no-inverting input terminal and inverting input terminal in real time. When the voltage of the no-inverting input 
terminal is higher than that of the inverting input terminal at the peak value of $V_{1}(t)$, $V_{1}(t)$ is output directly through the output terminal of TSX339 to control $Q_{1}$ turn on for a short time. When the output voltage $\left(V_{1}(t)\right)$ drops from a high value to the drain-source on-voltage of IRF5852, $\mathrm{Q}_{1}$ turns off automatically. During this short time, electric energy is transferred from $C_{p}$ to $L_{1}$.

(2) The second circuit loop is composed of inductor $L_{1}$, capacitor $C_{i}$ and diode $D_{5}$. Compared with DSSH, the EDSSH circuit sets a low-power diode $\mathrm{D}_{5}$ in this circuit loop, which together with $\mathrm{C}_{\mathrm{i}}$ and $\mathrm{L}_{1}$ forms the reverse feedback blocking-up circuit (RFBC). It avoids the unstable power transfer efficiency of DSSH caused by $\mathrm{L}_{1}-\mathrm{C}_{\mathrm{i}}$ oscillation and ensures that power is only transferred from inductor $L_{1}$ to the capacitor $\mathrm{C}_{\mathrm{i}}$ in one way.

(3) The capacitor $\mathrm{C}_{\mathrm{i}}$, inductor $\mathrm{L}_{2}$, diode $\mathrm{D}_{6}$, ultra-low on-resistance MOSFET $\mathrm{Q}_{2}$ (representative switch $S_{2}$ ) and the control circuit of $S_{2}$ constitute the third circuit loop. Compared with DSSH, the EDSSH circuit has three improvements. First, the EDSSH circuit simplifies the switching control circuit and uses a simple structure and lowpower IC, a comparator MAX9064, five resistors and one capacitor. The control circuit of $S_{2}$ is composed of the low-power comparator MAX9064 and its peripheral circuit. The inverting input terminal does not need a reference voltage source due to its internal $V_{\text {ref }}(0.2 \mathrm{~V})$. Because the range of $\mathrm{V}_{\mathrm{CC}}$ of MAX9064 is 0.9 to $5.5 \mathrm{~V}$, but $V_{C i}(t)$ reaches $14 \mathrm{~V}, V_{C i}(t)$ is connected to the no-inverting input of MAX9064 after depressurization through series resistance $R_{5}, R_{6}$ and $R_{7}$. Secondly, other passive components also have low power consumption, such as ultra-low on-resistance MOSFET $\mathrm{Q}_{2}$ and diode $\mathrm{D}_{6}$ (IN60P). Thirdly, the control circuit of switch $\mathrm{S}_{2}$ with low power and does not need an additional power supply but is supplied by the output voltage $V_{C i}(t)$, and it can control $S_{2}$ turn on when the voltage of $V_{C i}(t)$ reaches the maximum after a brief time, and $S_{2}$ turns off when the current in the inductor $L_{2}$ reaches the maximum. That is, when the $V_{C i}(t)$ reaches the maximum (at this time, the no-inverting input voltage of MAX9064 just exceeds its $\left.\mathrm{V}_{\text {ref }}(0.2 \mathrm{~V})\right)$, MAX9064 outputs high voltage for a short time $\left(\mathrm{t}_{S 20 n}\right)$ and controls $\mathrm{S}_{2}$ turn on. The $\mathrm{t}_{S 20 n}$ is determined by the discharge time of the $\mathrm{RC}$ discharge circuit composed of $\mathrm{R}_{9}$ and $\mathrm{C}_{2}$, and it must be equal to one fourth of the oscillation period of the LC oscillation circuit composed of $\mathrm{L}_{2}$ and $\mathrm{C}_{\mathrm{i}}$ to ensure that the electric energy of $C_{i}$ is transmitted to $L_{2}$ in one way automatically.

(4) The inductor $L_{2}$, diode $D_{7}$ and capacitor $C_{S}$ constitute the buck-boost circuit, which is used to charge $\mathrm{C}_{\mathrm{S}}$. It inherits from DSSH and can be used to broaden the load matching ability of the circuit.

\subsection{Working Process and Control Strategy of EDSSH Circuit}

Assume that the piezoelectric structure resonates with the sinusoidal excitation of frequency $(\omega)$, and the corresponding vibration period is $T_{P}$. The working process of the circuit is shown in Figure 4. The waveform of nodes of the EDSSH circuit in one power harvesting cycle is shown in Figure 5.

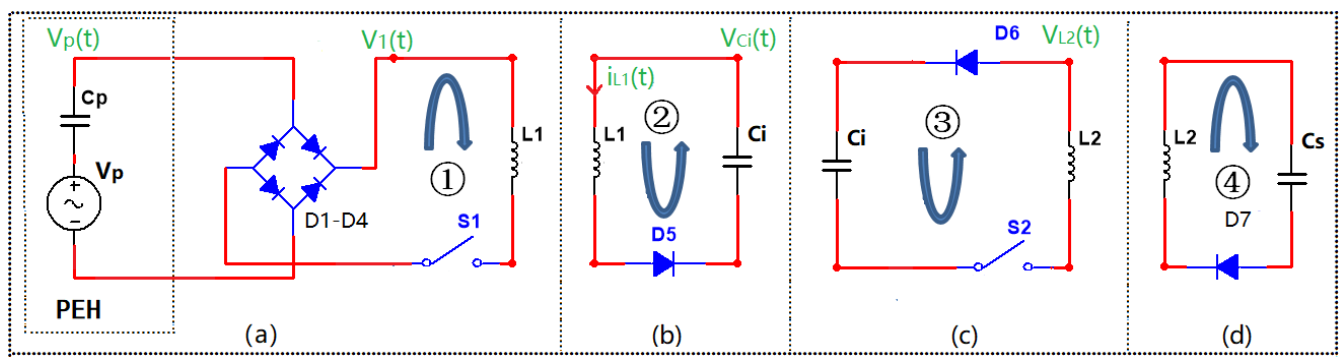

Figure 4. The working process of the EDSSH circuit. (a) The first stage; (b) The second stage; (c) The third stage; (d) The fourth stage. 


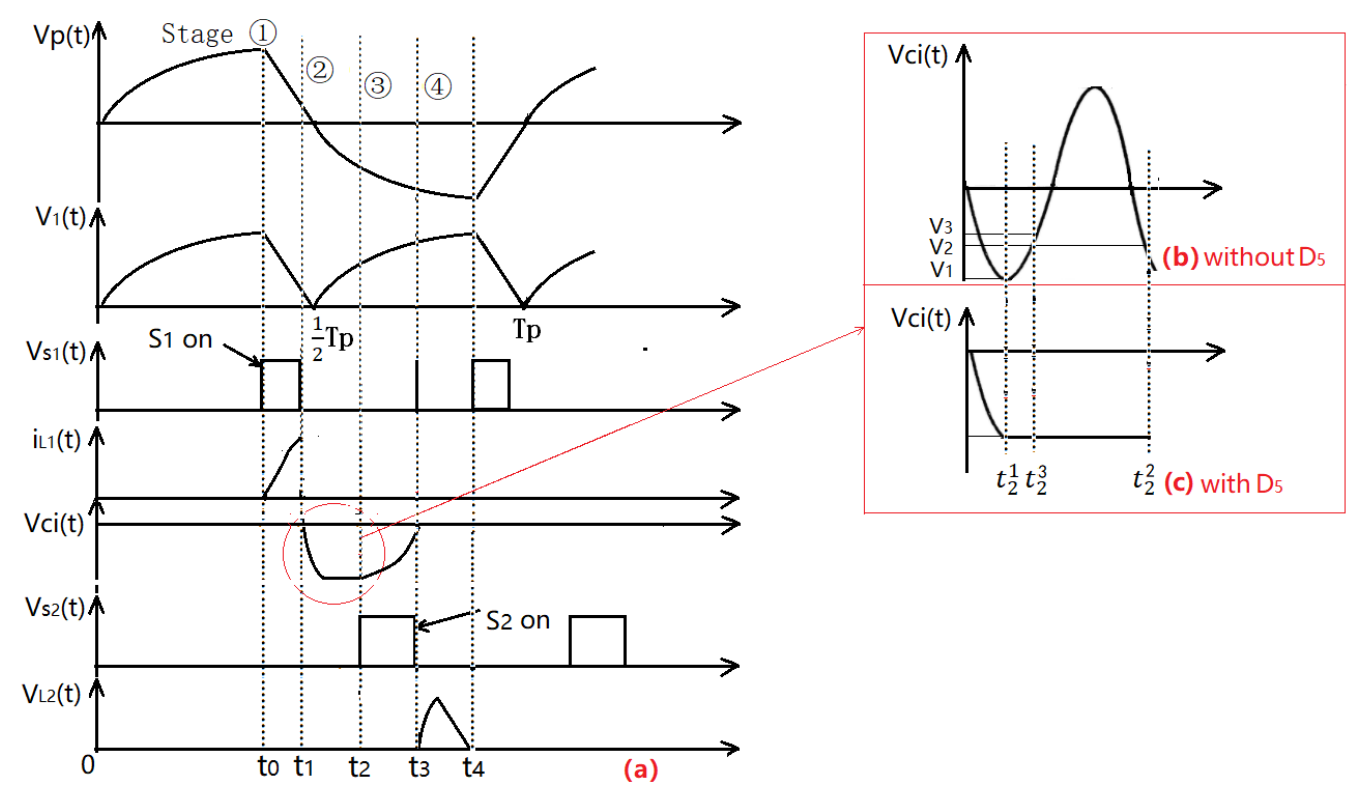

Figure 5. The waveform of nodes of the EDSSH circuit in one cycle. (a) The nodal waveforms; (b) The $V_{C i}(t)$ of DSSH circuit without $\mathrm{D}_{5} ;(\mathbf{c})$ The $V_{C i}(t)$ of EDSSH circuit with $\mathrm{D}_{5}$.

Take a vibration period in resonance as an example to illustrate the operation process and control strategy of the circuit. (1) The first stage (Figure $4 a, 0-t_{1}$ of Figure $5 a$ ): In the initial stage of system vibration, the switches $S_{1}$ and $S_{2}$ are turned off, and the PEH is in the vibration state without load coupling. Voltage is generated across the PEH due to structural bending. When the vibration amplitude and the voltage of the $\mathrm{PEH}\left(V_{p}(t)\right)$ reach the maximum at $t_{0}$ of the positive half period, the control circuit of $S_{1}$ controls $S_{1}$ turn on automatically until it detects the maximum of $V_{1}(t)$. The electric energy of the PEH is transferred from the $C_{p}$ to $L_{1}$ in one way in the $C_{p}-L_{1}$ loop at this time. The electric energy transfer is complete when $V_{1}(t)$ drops to near zero; at this time the control circuit of $S_{1}$ turns off $S_{1}$ automatically. (2) The second stage (Figure $4 b, t_{1}-t_{2}$ of Figure $5 a$ ): $L_{1}$ transfers electric energy to $C_{i}$ automatically due to LC oscillation. Due to the built-in diode $D_{5}$ in the $L_{1}-C_{i}$ loop, the electric energy of $L_{1}$ can only be transferred from $L_{1}$ to $C_{i}$ in one direction, and the loop does not have reverse feedback from $C_{i}$ to $L_{1}$ caused by multiple LC oscillations. (3) The third stage (Figure $4 c, t_{2}-t_{3}$ of Figure $5 a$ ): The control circuit of $S_{2}$ controls $\mathrm{S}_{2}$ turn on when the voltage of $V_{C i}(t)$ reaches the maximum for a brief time, and $\mathrm{S}_{2}$ turns off when the current in the inductor $\mathrm{L}_{2}$ reaches the maximum. $\mathrm{C}_{\mathrm{i}}$ transfers electric energy to $L_{2}$ automatically due to LC oscillation during this time. (4) The fourth stage (Figure $4 d, t_{3}-t_{4}$ of Figure $5 a$ ): Electric energy is stored on $C_{S}$ of the buck-boost circuit.

\section{Circuit Modeling}

In the case of resonance of the PEH, suppose that the frequency of $V_{P}(t)$ is $\omega$ and the period is $T_{p}$. In $T_{p}$ time, the circuit harvests electric energy from PEH twice in a vibration cycle. For the convenience of introduction, the energy conversion relationship of the circuit in an energy extraction cycle is modeled.

\subsection{The $C_{p}-L_{1}$ Loop}

The main circuit of the $\mathrm{Cp}-\mathrm{L}_{1}$ loop. Combined with the research of Zhang [84], suppose the excitation signal is $f(t)=-F_{0} \cos (\omega t)$, where $F_{0}$ and $\omega$ are the amplitude and frequency of the signal, respectively. The end displacement of the piezoelectric beam structure is $u(t)=-U_{P} \cos (\omega t+\varphi)$, where $U_{P}$ is the amplitude of the displacement signal and $\varphi$ is the phase angle between $u(t)$ and $f(t)$. In the case of without circuit coupling, the voltage across the PEH is $V_{P}(t)=V_{P}[1-\cos (\omega t+\varphi)]$, where $V_{P}=\chi U_{P} / C_{P}$ is the voltage across the PEH when it reaches the extreme value of displacement, $\chi$ is the 
electromechanical coupling coefficient and $C_{P}$ is the piezoelectric clamping capacitance. There is an energy transfer in half a vibration period, and the electric energy generated by the $\mathrm{PEH}$ is $E_{P}=\frac{1}{2} C_{P} V_{P}^{2}$. Electric energy consumed by the rectifier bridge in this period is $E_{D 1-4}=2 C_{P} V_{P} V_{d}$, where $V_{d}$ is the forward voltage drop of a diode.

Regarding the power consumption of the control circuit of $S_{1}\left(E_{T S X}\right)$, the control circuit of $S_{1}$ is dormant most of the time and does not consume electric energy. It only works for a very short time $\left(t_{S 10 n}\right)$ when $V_{P}(t)$ reaches the peak. The $t_{S 1 o n}$ is equal to $1 / 4$ of the period ( $T_{C p-L 1}=2 \pi \sqrt{C_{P} L_{1}}$ ) of the LC oscillation circuit composed of $C_{P}$ and $L_{1}$. The power loss of the control circuit of $S_{1}$ consists of four parts: (1) The power loss of input terminal of TSX339 $\left(E_{T S X-i}\right)$ is mainly the electric energy consumption on resistor $\mathrm{R}_{1}$ and $R_{2}$. The maximum power supply of TSX 339 is $18 \mathrm{~V}$, the maximum input voltage is $16 \mathrm{~V}$, the typical value of input resistance is $R_{T S X i}=10^{12} \Omega$ and the typical value of the current at the forward input terminal and reverse input terminal is $I_{T S X i}=1 p A$. Therefore, the input terminal electrical power consumption of TSX339 is $E_{T S X-i}=\frac{1}{4} T_{C p-L 1} I_{T S X i}^{2}\left(R_{1}+R_{2}\right)$. (2) The power loss of output terminal of TSX339 $\left(E_{T S X-o}\right)$ is mainly the electric energy consumption on resistor $R_{3}$ and $R_{4}$. Since the gating voltage of IRF5852 is $5.5 \mathrm{~V}$ and the voltage amplitude of $V_{1}(t)$ is $12.26 \mathrm{~V}$, the resistance of variable resistor $R_{3}$ was set as $2.46 \mathrm{M} \Omega$. At this time the current flowing through $R_{3}$ and $R_{4}$ is $I_{T S X o}=V_{1}(t) /\left(R_{3}+R_{4}\right)$, and the power loss is $E_{T S X-o}=\int_{0}^{t_{S 10 n}} R_{3} * I_{T S X o}^{2} d t+\int_{0}^{t_{S 10 n}} R_{4} * I_{T S X o}^{2} d t=\int_{0}^{t_{S 10 n}} V_{1}(t) I_{T S X_{0}} d t$. (3) The power consumption of TSX339 itself $\left(E_{T S X-s}\right)$ : According to the electrical characteristics of TSX339, the typical current of its single comparator is $5 \mu \mathrm{A}$, so the consumed electric energy is $E_{T S X-s}=\int_{0}^{t_{S 10 n}} V_{1}(t) * 5 * 10^{-6} d t$. (4) The power loss on IRF5852 $\left(E_{T S X-Q 1}\right)$ : The typical on-resistance of IRF5852 is $0.09 \Omega$, so the power loss on IRF5852 is $E_{T S X-Q 1}=\int_{0}^{t_{S 10 n}} 0.09 i_{L 1}^{2}(t) d t$. Thus, the power consumption of the control circuit of $S_{1}$ is $E_{T S X}=E_{T S X-i}+E_{T S X-o}+E_{T S X-S}+E_{T S X-Q 1}$.

Let the energy conversion coefficient of $C_{p}-L_{1}$ circuit loop be $\gamma_{1}$, then the electric energy transferred to the inductor $L_{1}$ at this time is:

$$
\begin{aligned}
\Delta E_{L 1} & =\left(\gamma_{1} E_{P}-E_{D 1-4}\right)-E_{T S X} \\
& =C_{P} V_{P}\left(\frac{1}{2} \gamma_{1} V_{P}-2 V_{d}\right)-E_{T S X}=\chi U_{P}\left(\frac{\gamma_{1} \chi U_{P}}{2 C_{P}}-2 V_{d}\right)-E_{T S X}
\end{aligned}
$$

\subsection{The $L_{1}-C_{i}$ Circuit}

Only one charge occurs on $C_{i}$ in a half cycle due to the influence of reverse feedback blocking-up caused by diode $D_{5}$. Assuming that the capacitance value of $C_{i}$ is $C_{i}$, the initial voltage value of $C_{i}$ is $V_{c i}$, and the voltage increase value of $C_{i}$ after charging is $\Delta V_{C i}$ because the positive pole of the negative capacitance $C_{i}$ is grounded, so $C_{i}<0, V_{c i}<0$ and $\Delta V_{C i}<0$, and the increased value of electric energy of $C_{i}$ after the charging is completed is:

$$
\Delta E_{C i}=\frac{1}{2} C_{i}\left(V_{C i}+\Delta V_{C i}\right)^{2}-\frac{1}{2} C_{i} V_{C i}{ }^{2}=\frac{1}{2} C_{i} \Delta V_{C i}{ }^{2}+C_{i} V_{C i} \Delta V_{C i}
$$

The charging current only flows through the diode $\mathrm{D}_{5}$ once in half a cycle, so the energy consumed by the diode $\mathrm{D}_{5}$ in this process is $E_{D 5}=\int_{a}^{b} V_{d} * i_{C i}(t) d t=-\int_{a}^{b} V_{d} * C_{i} d V_{C i}(t)=$ $-C_{i} V_{d} \Delta V_{C i}$, where $\mathrm{a}$ and $\mathrm{b}$ are the starting and ending time of charging of capacitor $C_{i}$, respectively. Assume that the efficiency of electric energy transfer of the loop is $\gamma_{2}$. According to the law of conservation of energy, we can obtain $\Delta E_{C i}=\gamma_{2} \Delta E_{L 1}-E_{D 5}$, and it can also be expressed in this way:

$$
C_{i} \Delta V_{C i}^{2}+2 C_{i}\left(V_{C i}-V_{d}\right) \Delta V_{C i}-2 \gamma_{2} \Delta E_{L 1}=0
$$

By solving Equation (3), we can obtain $\Delta V_{C i}$ as follows:

$$
\Delta V_{C i}=\sqrt{\left(V_{d}-V_{C i}\right)^{2}+\frac{2 \gamma_{2} \Delta E_{L 1}}{C_{i}}}+\left(V_{d}-V_{C i}\right)
$$


It can be seen from Formula (4) that $\Delta V_{C i}$ is only related to $U_{P}$ when parameters of the circuit are determined because $\Delta E_{C i}$ is only related to $\Delta V_{C i}$, and $\Delta E_{C i}$ is only related to $U_{P}$. According to Tang [32], the expression of $U_{P}$ is as follows:

$$
U_{P}=\frac{F_{0}}{\sqrt{\left(\eta \omega+\frac{4 \chi^{2}}{\pi C_{P}}\right)^{2}+\left(K-M \omega^{2}+\frac{\chi^{2}}{C_{P}}\right)^{2}}}
$$

where $M, K$ and $\eta$ are the modal mass, modal stiffness and modal damping ratio of the $\mathrm{PEH}$, respectively. By substituting Formulas (4) and (5) into Formula (2), we can obtain $\Delta E_{C i}$.

\subsection{The $C_{i}-L_{2}$ Loop}

Regarding the power consumption of the control circuit of $S_{2}\left(E_{M A X}\right)$, the control circuit of $S_{2}$ is dormant most of the time and does not consume electric energy. It only works for a very short time $\left(t_{S 20 n}\right)$ when $V_{C i}(t)$ reaches the peak. The $t_{S 2 o n}$ is equal to $1 / 4$ of the period $\left(T_{C i-L 2}=2 \pi \sqrt{C_{i} L_{2}}\right)$ of the LC oscillation circuit composed of $C_{i}$ and $L_{2}$. The power loss of the control circuit of $S_{2}$ consists of four parts: (1) The power loss of the input terminal of MAX9064 ( $\left.E_{M A X-i}\right)$ is mainly the electric energy consumption on resistors $R_{5}, R_{6}$ and $R_{7}$. The maximum voltage of $V_{C i}(t)$ is $13.87 \mathrm{~V}$. The input voltage range of MAX9064 is 0 to $5.5 \mathrm{~V}$. In order to make the supply voltage and forward input voltage of MAX9064 reach 5.5 and $0.2 \mathrm{~V}$, respectively, when $V_{C i}(t)$ reaches $13.87 \mathrm{~V}$, the resistance of $\mathrm{R}_{5}, \mathrm{R}_{6}$ and $\mathrm{R}_{7}$ was set as $0.1,2.65$ and $4.18 \mathrm{M} \Omega$, respectively. At this time the current flowing through $R_{3}$ and $R_{4}$ is $I_{M A X i}=V_{C i}(t) /\left(R_{5}+R_{6}+R_{7}\right)$. Therefore, the input terminal electrical power consumption of MAX9064 is $E_{M A X-i}=\int_{0}^{t_{520 n}}\left(R_{5}+R_{6}+R_{7}\right) I_{M A X i}^{2} d t$. (2) The power loss of output terminal of MAX9064 ( $\left.E_{M A X-o}\right)$ is mainly the electric energy consumption on resistors $R_{8}$, $R_{9}$ and $R_{10}$. To ensure that the electric energy of $C_{i}$ is just transferred to $L_{2}$, the conduction time of switch $S_{2}$ must be just equal to $\frac{1}{4} T_{C i-L 2}$; that is, the discharge time $T_{C 2-R 9}$ of the discharge circuit composed of $C_{2}$ and $R_{9}$ is equal to $\frac{1}{4} T_{C i-L 2}$. According to this, $R_{8}, R_{9}$ and $R_{10}$ were set as $0.1,1$ and $2 \mathrm{M} \Omega$, respectively. Therefore, the power loss on $R_{8}$ and $\mathrm{R}_{9}$ is $E_{R 8}=\frac{1}{4} T_{C i-L 2} * R_{8} *\left(\frac{5.5}{R_{8}+R_{9}}\right)^{2}$ and $E_{R 9}=\frac{1}{4} T_{C i-L 2} * R_{9} *\left(\frac{5.5}{R_{8}+R_{9}}\right)^{2}$, respectively, and the power loss on $R_{10}$ is equal to the electric energy on $C_{2}\left(E_{C 2}=\frac{1}{2} C_{2} *(5.5)^{2}\right)$. Thus, $E_{M A X-o}=E_{R 8}+E_{R 9}+E_{C 2}$. (3) The power consumption of MAX9064 itself $\left(E_{M A X-s}\right)$ : According to the electrical characteristics of MAX9064, the maximum value of operating current is $100 \mathrm{nA}$, so the consumed electric energy is $E_{M A X-s}=\int_{0}^{t_{s 20 n}} V_{C i}(t) * 0.1 * 10^{-6} d t$. (4) The power loss on IRF5852 ( $\left.E_{M A X-Q 2}\right)$ : The typical on-resistance of IRF5852 is $0.09 \Omega$, so the power loss on IRF5852 is $E_{M A X-Q 2}=\int_{0}^{t_{S 20 n}} 0.09 i_{L 2}^{2}(t) d t$. Therefore, the power consumption of the control circuit of $S_{1}$ is $E_{M A X}=E_{M A X-i}+E_{M A X-o}+E_{M A X-s}+E_{M A X-Q 2}$.

Assuming that the residual electric energy of $C_{i}$ is zero when the energy transfer is completed, since there is only one discharge process on $C_{i}$ during this time, the electric energy consumed on $D_{6}$ is:

$$
E_{D 6}=\int_{a}^{b} V_{d} * i_{L 2} C_{C i} \Delta V_{C i}{ }^{2}(t) d t=C_{i} V_{d} \Delta V_{i}
$$

Suppose that the efficiency of electric energy transfer of the circuit is $\gamma_{3}$, then the electric energy transferred to $L_{2}$ is:

$$
\Delta E_{L 2}=\gamma_{3} \Delta E_{C i}-E_{D 6}-E_{M A X}
$$

\subsection{The Buck-Boost Circuit}

Let the capacitance, the initial voltage and the increased voltage after a single energy conversion of $C_{S}$ be $C_{S}, V_{C S 0}$ and $\Delta V_{C s}$, respectively. Suppose that the power transfer 
efficiency of the circuit is $\gamma_{4}$, then according to the law of conservation of energy, we have $\Delta E_{C S}=\gamma_{4} \Delta E_{L 2}-E_{D 7}$, and it can also be expressed as:

$$
C_{S} \Delta V_{C S}^{2}+2 C_{S}\left(V_{C s 0}+V_{d}\right) \Delta V_{C S}-2 \gamma_{4} \Delta E_{L 2}=0
$$

By solving Formula (8), we can obtain $\Delta V_{C_{S}}$ as follows:

$$
\Delta V_{C s}=\sqrt{\left(V_{d}+V_{C s 0}\right)^{2}+\frac{2 \gamma_{4} \Delta E_{L 2}}{C_{s}}}-\left(V_{d}+V_{C s 0}\right)
$$

We can obtain $\Delta V_{C s}$ by substituting Formula (7) into Formula (9). Then the electric energy increment on the charging capacitor Cs can be obtained as follows:

$$
\Delta E_{C s}=\frac{1}{2} C_{s}\left(V_{C s}+\Delta V_{C s}\right)^{2}-\frac{1}{2} C_{s} V_{C s}{ }^{2}=\frac{1}{2} C_{s} \Delta V_{C s}^{2}+C_{s} V_{C s 0} \Delta V_{C s} .
$$

According to the discussion above, the models of key parameters reflecting circuit performance are summarized as follows:

1. Voltage on $C_{S}$ (charging voltage of the circuit)

$$
V_{C s}=V_{C s}{ }^{-}+\Delta V_{C s}
$$

2. Electrical power of $C_{S}$ (electric energy harvesting power of the circuit)

$$
P_{C s}=\frac{\Delta E_{C s}}{\Delta t}=\frac{2 \Delta E_{C s}}{T_{P}}=\frac{C_{s} \Delta V_{C s}^{2}+2 C_{s} V_{C s 0} \Delta V_{C s}}{T_{P}}
$$

3. Power Budget

The calculation formula of average power is $\bar{P}=\frac{E}{T}$. During an energy extraction cycle with a duration of $\frac{1}{2} T_{P}$, the electric power generated by the piezoelectric vibrator is:

$$
\bar{P}_{\text {in }}=E_{P} /\left(0.5 T_{P}\right)
$$

\begin{tabular}{|c|c|c|}
\hline Object & Power Loss & Unit \\
\hline$D_{1}+D_{2}+D_{3}+D_{4}$ & $\left(2 C_{P} V_{P} V_{d}\right) /\left(0.5 T_{P}\right)$ & \multirow{13}{*}{ W } \\
\hline $\mathrm{R}_{1}+\mathrm{R}_{2}$ & {$\left[\frac{1}{4} T_{C p-L 1} I_{T S X i}^{2}\left(R_{1}+R_{2}\right)\right] /\left(0.5 T_{P}\right)$} & \\
\hline $\mathrm{R}_{3}+\mathrm{R}_{4}$ & {$\left[\int_{0}^{t} t_{\text {slon }}\left(R_{3}+R_{4}\right) * I_{T S X_{0}}^{2} d t\right] /\left(0.5 T_{P}\right)$} & \\
\hline TSX339 & {$\left[\int_{0}^{t_{\text {S1on }}} V_{1}(t) * 5 * 10^{-6} d t\right] /\left(0.5 T_{p}\right)$} & \\
\hline $\mathrm{D}_{5}$ & {$\left[C_{i} V_{C i} V_{d}\right] /\left(0.5 T_{P}\right)$} & \\
\hline $\mathrm{Q}_{1}$ & {$\left[\int_{0}^{t_{S 1 o n}} 0.09 i_{L 1}^{2}(t) d t\right] /\left(0.5 T_{P}\right)$} & \\
\hline$R_{5}+R_{6}+R_{7}$ & {$\left[\int_{0}^{t_{520 n}}\left(R_{5}+R_{6}+R_{7}\right) I_{M A X i}^{2} d t\right] /\left(0.5 T_{P}\right)$} & \\
\hline $\mathrm{R}_{8}+\mathrm{R}_{9}$ & {$\left[\frac{1}{4} T_{C i-L 2} *\left(R_{8}+R_{9}\right) *\left(\frac{5.5}{R_{8}+R_{9}}\right)^{2}\right] /\left(0.5 T_{P}\right)$} & \\
\hline $\mathrm{R}_{10}$ & {$\left[\frac{1}{2} C_{2} *(5.5)^{2}\right] /\left(0.5 T_{P}\right)$} & \\
\hline MAX9064 & {$\left[\int_{0}^{t_{S 20 n}} V_{C i}(t) * 0.1 * 10^{-6} d t\right] /\left(0.5 T_{P}\right)$} & \\
\hline $\mathrm{Q}_{2}$ & {$\left[\int_{0}^{t_{S 20 n}} 0.09 i_{L 2}^{2}(t) d t\right] /\left(0.5 T_{P}\right)$} & \\
\hline$D_{6}$ & {$\left[C_{i} V_{C i} V_{d}\right] /\left(0.5 T_{P}\right)$} & \\
\hline $\mathrm{D}_{7}$ & {$\left[C_{s} V_{C_{S}} V_{d}\right] /\left(0.5 T_{P}\right)$} & \\
\hline
\end{tabular}

The electric power losses of $\mathrm{D}_{1}-\mathrm{D}_{7}, \mathrm{R}_{1}-\mathrm{R}_{10}$, TSX339, MAX9064, $\mathrm{Q}_{1}$ and $\mathrm{Q}_{2}$ during an energy extraction cycle with a duration of $\frac{1}{2} T_{P}$ are shown in Table 1 .

Table 1. Power budget. 


\subsection{Validation of the Mode}

In order to verify the accuracy of the model, the calculation results were compared with the existing literature and simulation results using the software MULTISIM. Parameters of the circuit are shown in Table 2.

Table 2. Parameters of the circuit.

\begin{tabular}{|c|c|c|}
\hline Object & Parameter & Value \\
\hline \multirow{6}{*}{ PEH } & $V_{p}$ & 12.26 \\
\hline & Capacitance, $C_{P}(\mathrm{nF})$ & 62.36 \\
\hline & Modal mass, $M(\mathrm{~kg})$ & 1 \\
\hline & Modal stiffness, $K(\mathrm{kN} / \mathrm{m})$ & 22.18 \\
\hline & Modal damping, $\eta(\mathrm{N} / \mathrm{m})$ & 2.34 \\
\hline & Amplitude of modal force, $F_{0}(\mathrm{~N})$ & 0.13 \\
\hline \multirow{3}{*}{$\mathrm{D}_{1} \sim \mathrm{D}_{7}$} & & IN60P \\
\hline & Forward voltage drop, $V_{d}(\mathrm{~V})$ & 0.24 \\
\hline & $R_{1}, R_{2}(\mathrm{~K} \Omega)$ & 200 \\
\hline \multirow{6}{*}{ Resistor } & $R_{3}(\mathrm{M} \Omega)$ & 2.46 \\
\hline & $R_{4}, R_{10}(\mathrm{M} \Omega)$ & 2 \\
\hline & $R_{5}(\mathrm{M} \Omega)$ & 4.09 \\
\hline & $R_{6}(\mathrm{M} \Omega)$ & 2.75 \\
\hline & $R_{7}, R_{8}(\mathrm{M} \Omega)$ & 0.1 \\
\hline & $R_{9}(\mathrm{M} \Omega)$ & 1 \\
\hline \multirow{4}{*}{ Capacitor } & $C_{1}(\mathrm{pF})$ & 300 \\
\hline & $C_{2}(\mathrm{pF})$ & 10 \\
\hline & $C_{S}(\mathrm{mF})$ & 1 \\
\hline & $C_{i}(\mathrm{nF})$ & 30 \\
\hline \multirow{2}{*}{ IC } & $\mathrm{U}_{1}$ & TSX339 \\
\hline & $\mathrm{U}_{2}$ & MAX9064 \\
\hline $\mathrm{Q}_{1} \sim \mathrm{Q}_{2}$ & & IRF5852 \\
\hline Inductor & $L_{1}, L_{2},(\mathrm{mH})$ & 1 \\
\hline
\end{tabular}

\section{Comparison with the Existing Literature}

Taking $k_{m}{ }^{2}=\chi^{2} /\left(K C_{P}\right)$ as the coupling factor of the $\mathrm{PEH}$, the calculation results of present model were compared with Tang's model [85] in terms of the influence of excitation frequency $(\omega)$ on amplitude voltage of the PEH $\left(V_{P}\right)$ in case $k_{m}^{2}=0.0015$ (weak coupling), 0.015 (medium coupling) and 0.15 (strong coupling). The results are shown in Figure 6, it can be seen that the error is less than $1 \%$. Moreover, the strongest response of the EDSSH circuit to the PEH occurs in the case of medium coupling, and the corresponding output voltage amplitude and excitation frequency are $12.26 \mathrm{~V}$ and $23.88 \mathrm{~Hz}$, respectively.

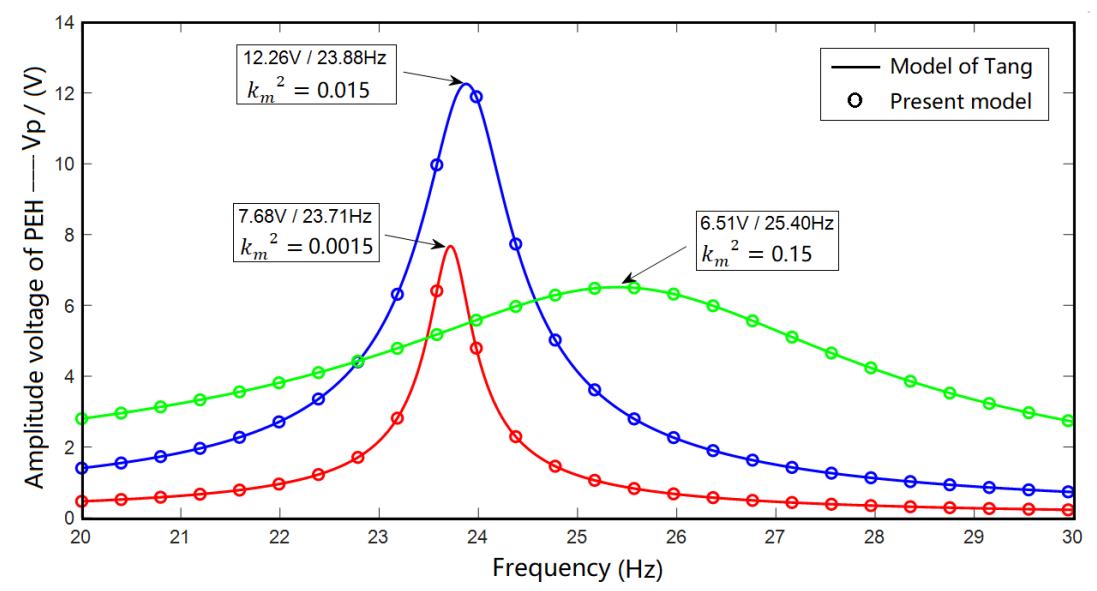

Figure 6. Comparison of the calculation results of present model with the calculation results of existing literature in three coupling cases. 


\section{Comparison with the Simulation Results}

The calculation results of present model were compared with the simulation results of MULTISIM in terms of the voltage across $C_{S}$ after charging for $60 \mathrm{~s}$ in three coupling cases. The results are shown in Figure 7. It can be seen that the voltage across $C_{S}\left(V_{C_{S}}\right)$ calculated by present model in three coupling cases is $1.86,4.48$ and $1.59 \mathrm{~V}$, and the simulation results are $1.58,3.86$ and $1.33 \mathrm{~V}$ with errors of $17.72 \%, 16.06 \%$ and $19.55 \%$, respectively, which shows that the present model has good prediction ability. However, the simulation result is lower than the calculation result of present model. The main reason is that the loss of energy in each circuit is not fully considered in the model, but these factors are included in the electronic component parameter model of MULTISIM.
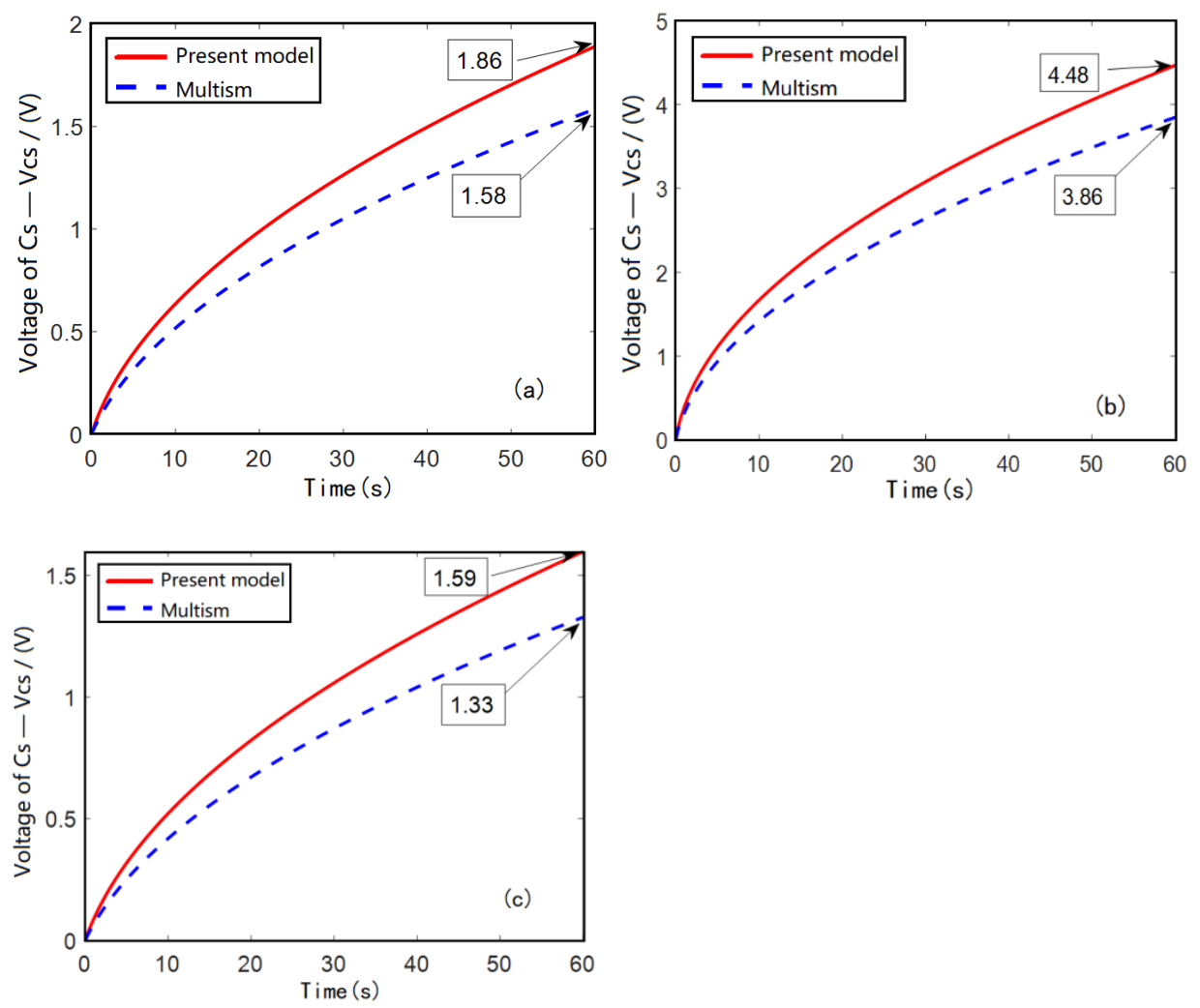

Figure 7. Comparison of the calculation results of present model with simulation results of MULTISIM in three coupling cases; (a) $k_{m}^{2}=0.0015$, (b) $k_{m}^{2}=0.015$, (c) $k_{m}^{2}=0.15$.

\section{Simulation and Experiment}

\subsection{Simulation of Rectifier Bridge}

MULTISIM software was used to simulate the circuit (Figure 3). Figure 8 shows the waveform of the output voltage $\left(V_{P}(t)\right.$, red curve) generated by the PEH after being excited and the waveform of the output voltage $\left(V_{1}(t)\right.$, blue curve) of the rectifier bridge. It can be seen that the rectifier bridge rectifies the AC sinusoidal signal of $V_{P}(t)$ into the DC signal $\left(\left(V_{1}(t)\right)\right.$.

\subsection{Simulation of Control Circuit of $S_{1}$}

The control circuit of $S_{1}$ consists of comparator TSX339, resistors $R_{1}, R_{2}, R_{3}$ and capacitor $C_{1}$. The no-inverting input voltage of TSX339 is represented by $V_{U 1(t)}^{+}$, the inverting input voltage is represented by $V_{U 1(t)}^{-}$and the output voltage is represented by $V_{U 1(t)}^{\text {out }}$. $V_{U 1(t)}^{o u t}$ and $V_{1}(t)$ are the same. The main function of the circuit is to automatically make the $V_{U 1(t)}^{\text {out }}$ high voltage when $V_{1}(t)$ reaches its peak value. $V_{U 1(t)}^{\text {out }}$ controls the conduction of field-effect transistor Q1 (IRF5852) for a short duration at the same time. Electrical energy 
on $\mathrm{C}_{\mathrm{P}}$ must be transmitted to $\mathrm{L}_{1}$ in one way. The waveforms of $V_{U 1(t)}^{+}, V_{U 1(t)}^{-}$and $V_{U 1(t)}^{\text {out }}$ are shown in Figure 9. It can be seen that $V_{U 1(t)}^{o u t}$ is low voltage due to $V_{U 1(t)}^{+}$being lower than $V_{U 1(t)}^{-}$in the period from 0 to $t_{0}$. During this period, IRF5852 is turned off. When $V_{1}(t)$ reaches its peak value at $\mathrm{t}_{0}, V_{U 1(t)}^{\text {out }}$ becomes higher than drain-source on-voltage of IRF5852 due to $V_{U 1(t)}^{+}$being higher than $V_{U 1(t)}^{-}$. Then IRF5852 turns on automatically because $V_{U 1(t)}^{\text {out }}$ is high voltage. When $V_{1}(t)\left(V_{U 1(t)}^{\text {out }}\right)$ decreases to drain-source on-voltage of IRF5852 near $\mathrm{t}_{1}$, IRF5852 turns off automatically.

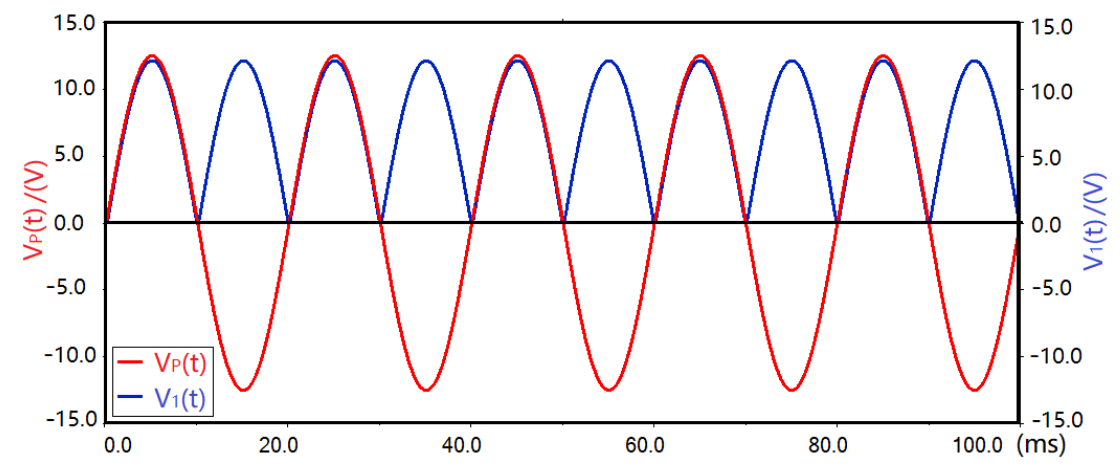

Figure 8. Output waveforms of the PEH and the rectifier bridge.

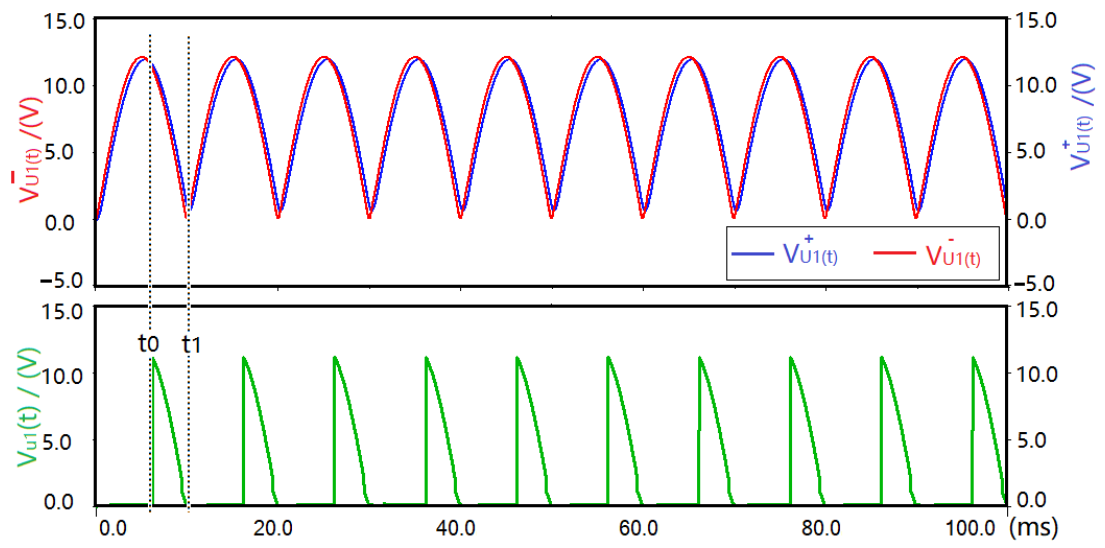

Figure 9. Waveforms of terminals of TSX339.

\subsection{Experiment}

\subsubsection{Experimental Platform}

The experimental platform is shown in Figure 10. The function generator1 (AFG3021C) generates a sine wave function (acceleration $0.5 \mathrm{~g}$ ) at the natural frequency of the PEH. The power amplifier amplifies the excitation signal generated by function generator1 to drive the exciter to vibrate, which makes the PEH produce resonance and output $12.26 \mathrm{~V} \mathrm{AC}$. Function generator2 simulates the control signal of switch $\mathrm{S}_{2}$. The designed circuit board (the circuit diagram is shown in Figure 3) is connected with the output terminal of the PEH to harvest the electric energy generated by the PEH. The oscilloscope (TDS2024C) is used to measure the voltage signal of the corresponding measuring point on the circuit board.

\subsubsection{Influence of RFBC on Electric Energy Harvesting Efficiency}

In order to verify that the RFBC in the EDSSH circuit can make the circuit maintain the optimal electric energy harvesting efficiency, taking the $L_{1}-C_{i}$ circuit as an example, the output voltage waveform of capacitor $C_{i}$ was measured in one energy harvesting cycle (0.01 s) when DSSH circuit was not configured with $\mathrm{D}_{5}$ (Figure 11a) and EDSSH circuit was configured with $\mathrm{D}_{5}$ (Figure $11 \mathrm{~b}$ ). 


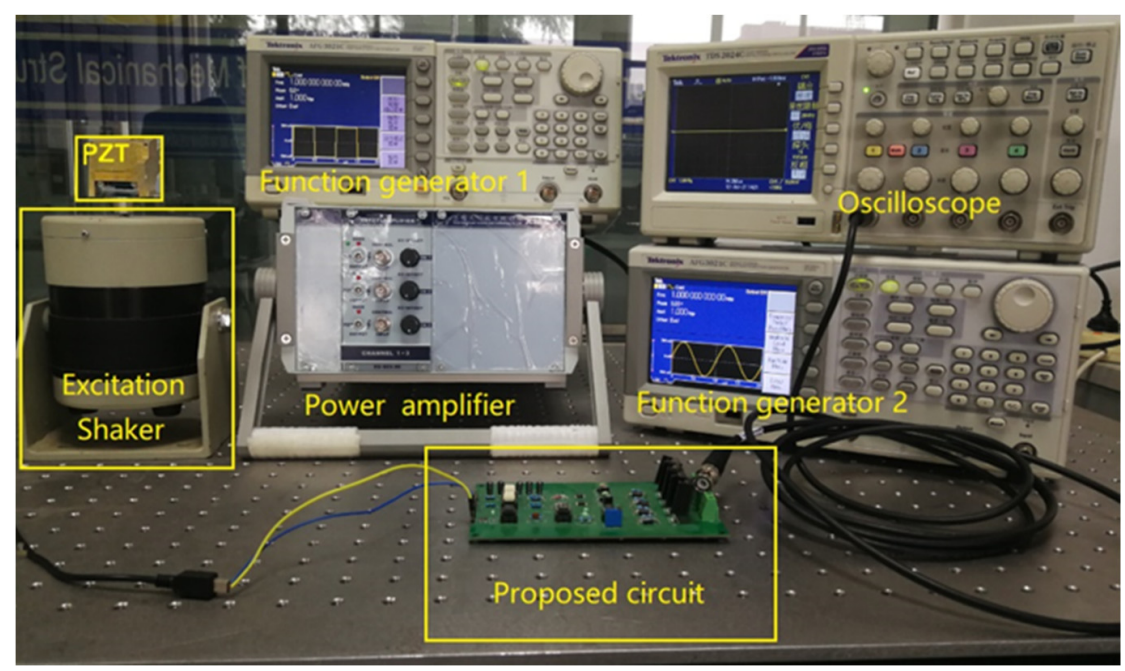

Figure 10. Experimental scheme and platform.
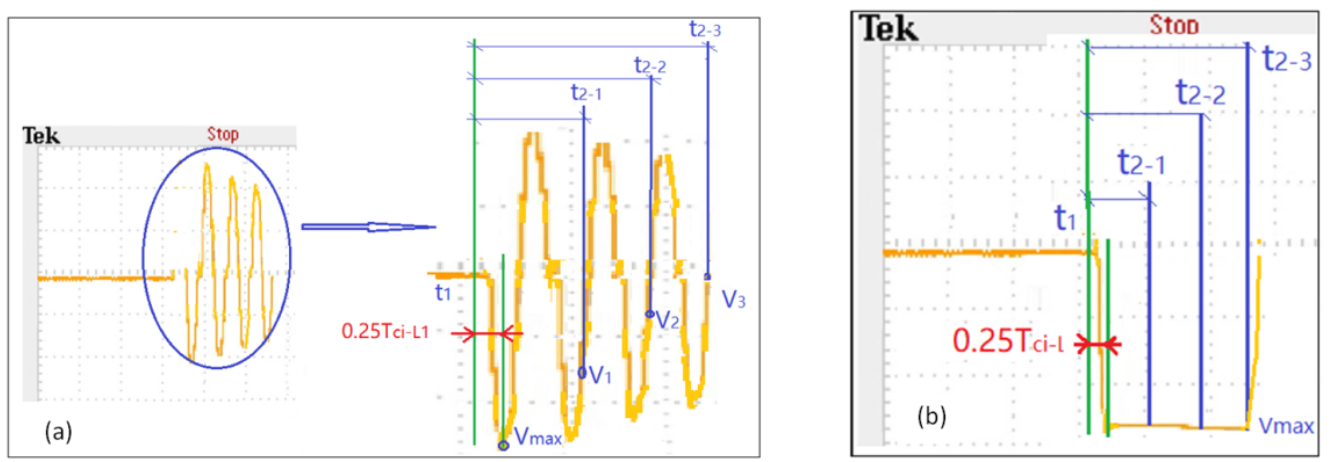

Figure 11. The waveform of $V_{C i}(t)$ in two cases: (a) without $\mathrm{D}_{5}$ in $\mathrm{DSSH}$ circuit (b) with $\mathrm{D}_{5}$ in EDSSH circuit.

It can be seen that $V_{C i}(t)$ can reach the optimal value $\left(\mathrm{V}_{\max }=-13.84 \mathrm{~V}\right)$ only when the duration of $t_{1}-t_{2}$ is equal to one fourth of the oscillation period $\left(0.25 * \mathrm{~T}_{\mathrm{ci}-\mathrm{L} 1}\right)$ of the $\mathrm{L}_{1}-\mathrm{C}_{\mathrm{i}}$ loop precisely. Otherwise, due to LC oscillation, the voltage values for $C_{i}$ are different at different times of $t_{2}$. For example, the voltages of $t_{2}$ at $t_{2-1}, t_{2-2}$ and $t_{2-3}$ are $\mathrm{V}_{1}(-7.86 \mathrm{~V})$, $\mathrm{V}_{2}(-3.74 \mathrm{~V})$ and $\mathrm{V}_{3}(-0.42 \mathrm{~V})$, which are $56.79 \%, 26.98 \%$ and $3.03 \%$ of the optimal value $\left(V_{\max }\right)$, respectively. That is to say, the efficiency of energy transferring of $L_{1}-C_{i}$ loop of DSSH circuit without $D_{5}$ cannot be kept at the optimal value. Figure $11 \mathrm{~b}$ is the waveform of the output voltage $\left(V_{C i}(t)\right)$ of the capacitor $C_{i}$ when the EDSSH circuit is configured with $D_{5}$. It can be seen that only if the duration of $t_{1}-t_{2}$ is more than one fourth of the oscillation period of $\mathrm{L}_{1}-\mathrm{C}_{\mathrm{i}}$ loop, the $\mathrm{L}_{1}-\mathrm{C}_{\mathrm{i}}$ circuit only has one-way power transfer from $\mathrm{L}_{1}$ to $\mathrm{C}_{\mathrm{i}}$; that is, after $L_{1}$ charges $C_{i}$, the voltage of $C_{i}$ keeps the optimal value $\left(V_{\max }\right)$ unchanged.

\subsubsection{Efficiency of EDSSH Circuit}

The voltage $V_{P}(t)$ of the $\mathrm{PEH}$ and the increased voltage $\Delta V_{C i}(t)$ of $\mathrm{C}_{\mathrm{i}}$ were measured with the experimental platform shown in Figure 10, and their amplitudes are $V_{P}$ and $\Delta V_{C i}$, respectively. The electric energy consumed by diode $D_{7}$ is $E_{D 7}=\int_{t_{0}}^{t_{1}} V_{d} * i_{C s}(t) d t=\int_{t_{0}}^{t_{1}} * C_{s} d V_{C_{s}}(t)=C_{i} V_{d} \Delta V_{C_{S}}$. It can be seen from Equation (9) that the value of $\Delta V_{C S}$ in each charging cycle is related to the voltage of capacitor $\left(C_{S}\right)$ and the charging time $(t)$. Thus, $E_{D 7}$ is not a constant but a variable related to $V_{C S}$ and $t$. The $V_{C s}$ of $C_{S}$ was measured after $60 \mathrm{~s}$ charging, and the results are shown in Table 3, where $\eta_{P E H-C_{i}}\left(\eta_{P E H-C_{i}}=\frac{\Delta E_{C i}}{E_{P}}=\frac{\frac{1}{2} C_{i} \Delta V_{C i}{ }^{2}}{\frac{1}{2} C_{P} V_{P}^{2}} * 100 \%\right)$ is the efficiency of the circuit from the PEH to $C_{\mathrm{i}}, \eta_{D 6-C_{S}}\left(\eta_{D 6-C_{s}}=\frac{\Delta E_{C s}}{\sum \Delta E_{C i}} * 100 \%\right)$ is the charging efficiency within $60 \mathrm{~s}$ of the circuit 
from $D_{6}$ to $C_{s}, \sum \Delta E_{C i}$ is the total electric energy accumulated on $C_{i}$ within $60 \mathrm{~s}$ charging time and $\eta\left(\eta=\eta_{P E H-C_{i}} * \eta_{D 6-C_{s}}\right)$ is the total efficiency of the circuit.

Table 3. Efficiency and nodal-voltage of EDSSH circuit.

\begin{tabular}{cccccc}
\hline$V_{P}(\mathrm{~V})$ & $\Delta V_{C i}(\mathrm{~V})$ & $\eta_{P E H-C_{i}}(\%)$ & $V_{C s}(\mathrm{~V}), 60 \mathrm{~s}$ & $\eta_{D 6-C_{s}}(\%)$ & $\eta(\%)$ \\
\hline 12.26 & -13.84 & 73.29 & 3.85 & 74.81 & 54.83 \\
\hline
\end{tabular}

\subsubsection{Efficiency Comparison between EDSSH and DSSH Circuits}

It can be seen from Figure 11 that the output voltage of the DSSH circuit is uncertain. The voltage of $\mathrm{C}_{\mathrm{S}}$ of EDSSH and DSSH circuits was measured after $60 \mathrm{~s}$ charging time five times, and the charging efficiency of each time was calculated, taking the average value. The results are shown in Table 4 , where $\bar{\eta}_{1}$ and $\bar{\eta}_{2}$ are the average charging efficiency of EDSSH and DSSH circuits, respectively. It can be seen that the average charging efficiency of the EDSSH circuit is 1.51 times than that of DSSH.

Table 4. Efficiency comparison between EDSSH circuit and DSSH circuit.

\begin{tabular}{ccccccc}
\hline \multicolumn{3}{c}{ EDSSH } & \multicolumn{3}{c}{ DSSH } \\
\hline Times & $V_{C s}(\mathrm{~V})$ & $\eta(\%)$ & $\bar{\eta}_{1}(\%)$ & $V_{C_{S}}(\mathrm{~V})$ & $\eta(\%)$ & $\bar{\eta}_{2}(\%)$ \\
\hline 1 & 3.84 & 54.51 & & 3.12 & 35.97 & \\
1 & 3.62 & 48.43 & & 2.15 & 17.08 & \\
3 & 3.74 & 51.69 & 52.16 & 3.54 & 46.31 & 34.55 \\
4 & 3.80 & 53.36 & & 3.78 & 52.80 & \\
5 & 3.78 & 52.81 & & 2.36 & 20.58 & \\
\hline
\end{tabular}

\section{Discussion}

\subsection{Advantages of EDSSH Circuit}

(1) The low-power design. The complex control module and special power module in the DSSH circuit are required. Compared with the control circuit of $S_{1}$ and $S_{2}$ in the DSSH circuit, the EDSSH circuit integrated a module of a control circuit of switch $\mathrm{S}_{1}$ and $S_{2}$ with simple structure and low-power IC. The control circuit of $S_{1}$ only comprises a comparator TSX339, three resistors and one capacitor. The maximum average power consumption of TSX339 is $0.96 \mu \mathrm{W}$ in one electrical energy extraction cycle when $V_{p}(t)$ reaches the maximum value of $12.26 \mathrm{~V}$. In addition, the power supply and input signal of the comparator TSX339 are from the output terminal rectifier $V_{1}$. The control circuit of $S_{2}$ only comprises a comparator MAX9064, four resistors and one capacitor. The maximum average power consumption of MAX9064 is lower than $1 \mu \mathrm{W}$ in one electrical energy extraction cycle when $V_{C i}(t)$ reaches the maximum value. In addition, the power supply and input signal of the comparator MAX9064 are from the $V_{C i}$. According to Section 4.3, the total average charging efficiency of the EDSSH circuit is $52.16 \%$ compared with $34.55 \%$ of that of the DSSH circuit.

(2) The high-efficiency design. The RFBC is used to keep the power harvesting efficiency at the optimal value. Diodes $\mathrm{D}_{5}$ and $\mathrm{D}_{6}$ are configured in the loop to avoid reverse feedback of electric energy caused by LC oscillations in one energy harvesting cycle. Taking the $\mathrm{L}_{1}-\mathrm{C}_{\mathrm{i}}$ circuit as an example, if $\mathrm{D}_{5}$ is not configured in the DSSH circuit, the duration of $t_{1}-t_{2}$ should be precisely controlled to be equal to one fourth of the oscillation period of $\mathrm{L}_{1}-\mathrm{C}_{\mathrm{i}}$. Otherwise, the voltage values of $\mathrm{C}_{\mathrm{i}}$ are different according to different time of $t_{2}$ (Figure $5 b$, the voltage on $C_{i}$ at $t_{2}^{1}, t_{2}^{2}$ and $t_{2}^{3}$ are $V_{1}, V_{2}$ and $V_{3}$, respectively), and the efficiency of electric energy transfer is uncertain. When the EDSSH circuit is configured with $D_{5}$, as long as the duration of $t_{1}-t_{2}$ is greater than one fourth of the oscillation period of $\mathrm{L}_{1}-\mathrm{C}_{\mathrm{i}}$, the $\mathrm{L}_{1}-\mathrm{C}_{\mathrm{i}}$ loop only has one-way power transfer from $L_{1}$ to $C_{i}$; that is, the voltage of $C_{i}$ remains unchanged after $L_{1}$ charging $C_{i}$ (Figure $5 c$ ) so as to maintain the optimal efficiency. 
(3) The adaptive design. Firstly, the control circuit of $S_{1}$ is in the sleep state most of the time and self-cold-starting and turns on for a short time when $V_{1}(t)$ reaches its peak value. The control circuit of $S_{2}$ is in the sleep state most of the time and self-cold-starting and turns on for a short time when $V_{C i}(t)$ reaches its peak value. Secondly, it can adapt to the wide frequency range of input sinusoidal voltage signal. The main reason is that the single energy acquisition time $T_{C}$ of the circuit is only $1.6004 \mathrm{~ms}$ (including $0.0124 \mathrm{~ms}$ of $\mathrm{C}_{\mathrm{P}}-\mathrm{L}_{1}$ loop, $0.0086 \mathrm{~ms}$ of $\mathrm{L}_{1}-\mathrm{C}_{\mathrm{i}}$ - loop, $0.0086 \mathrm{~ms}$ of $\mathrm{C}_{\mathrm{i}}-\mathrm{L}_{2}$ loop and $1.5708 \mathrm{~ms}$ of $\mathrm{L}_{2}-\mathrm{C}_{\mathrm{s}}$ - loop). As long as half of the cycle of the input sinusoidal voltage signal is longer than $T_{C}$, the acquisition process can be completed automatically. Therefore, the circuit can automatically adapt to the input sinusoidal voltage signal of 1 312.5 Hz. Lastly, the circuit features a buck-boost structure, which can automatically match various loads.

\subsection{Comparison of Charging Performance between EDSSH Circuit and DSSH Circuit}

Because of the RFBC, the power conversion efficiency of the $L_{1}-C_{i}$ loop and $C_{i}-L_{2}$ loop in the EDSSH circuit can be stabilized at the optimal value. The DSSH circuit, because it does not use this technology, exhibits loop reverse feedback, resulting in the reduction of power transfer efficiency. Here, we can compare the charging performance between the EDSSH circuit and DSSH circuit by using the established model (Formula (12) in this paper) and MULTISIM software. For example, the power transfer efficiency corresponding to $t_{2}^{2}$ and $t_{2}^{3}$ in Figure $5 \mathrm{a}$ is $\gamma_{2}=0.8$ and 0.6 . Set $C_{s}=1 \mathrm{mF}, k_{m}{ }^{2}=0.015$ and analyze the voltage of charging capacitor $\left(V_{C s}\right)$ after $60 \mathrm{~s}$ charging time under three conditions of $\gamma_{2}=1.0,0.8$ and 0.6. The results are shown in Figure $12 \mathrm{a}$, and it can be seen that $V_{C s}$ increases with the increase in $\gamma_{2}$. The influence of the normalization efficiency $\left(\hat{\gamma}_{2}\left(\gamma_{2} / \gamma_{2 \max }\right)\right)$ of $\gamma_{2}$ on the normalized power $\left(\hat{P}\left(P_{2} / P_{\text {max }}\right)\right)$ was analyzed. The results are shown in Figure $12 b$, and it can be seen that $\hat{P}$ increases with the increase in $\hat{\gamma}_{2}$. Similar to $\gamma_{2}$, the influence of $\gamma_{3}$ on $V_{C S}$ and the influence of the normalization efficiency $\left(\hat{\gamma}_{3}\left(\gamma_{3} / \gamma_{3 \max }\right)\right)$ of $\gamma_{3}$ on the normalized power $\left(\hat{P}\left(P_{3} / P_{\max }\right)\right)$ are shown in Figure $12 \mathrm{c}, \mathrm{d}$, respectively. The results show that $V_{C s}$ increases with the increase in $\gamma_{3}$ and $\hat{P}$ increases with the increase in $\hat{\gamma}_{3}$. This proves that the RFBC technology can significantly improve the amplitude of output voltage and keep the efficiency of each circuit at the optimal value.

\subsection{Influence of Capacitance of $C_{S}$ on Charging Performance}

The influence of capacitance of $C$ s on charging performance was analyzed based on the proposed circuit model (Formula (12)) and MULTISIM software. In the process of electric energy harvesting, the influence of the capacitance of $C_{s}$ on its charging voltage $V_{C_{s}}$ is shown in Figure 13. It can be seen that when the capacitance $C_{s}=100 \mu \mathrm{F}, 1 \mathrm{mF}$ and $10 \mathrm{mF}$, $V_{C s}$ reaches $14.76,4.48$ and $1.26 \mathrm{~V}$, respectively, after $60 \mathrm{~s}$ charging time. This indicates that the voltage on the charging capacitor increases faster with smaller capacitor $C_{s}$.

\subsection{Influence of Initial Voltage of $C_{s}$ on Charging Performance}

In the process of power harvesting, the initial capacitance of $C_{s}\left(V_{C s 0}\right)$ has a significantly influence on the increment of voltage $\left(\Delta V_{C S}\right)$ and voltage value $\left(V_{C s}\right)$ of the charging capacitor. Influence of initial voltage of $C$ s on charging performance can also be analyzed based on the proposed circuit model (Formula (12)) and MULTISIM software. As can be seen from Figure 14, when $V_{C s 0}$ is 0,5 and $10 \mathrm{~V}, V_{C s}$ reaches $4.48,5.16$ and $6.75 \mathrm{~V}$, respectively, after $60 \mathrm{~s}$ charging time. Figure 15 shows that when $V_{C s 0}$ increases from 0 to $10 \mathrm{~V}$, the voltage increase value of charging capacitor decreases from 4.48 to $1.75 \mathrm{~V}$ after $60 \mathrm{~s}$ charging time. 

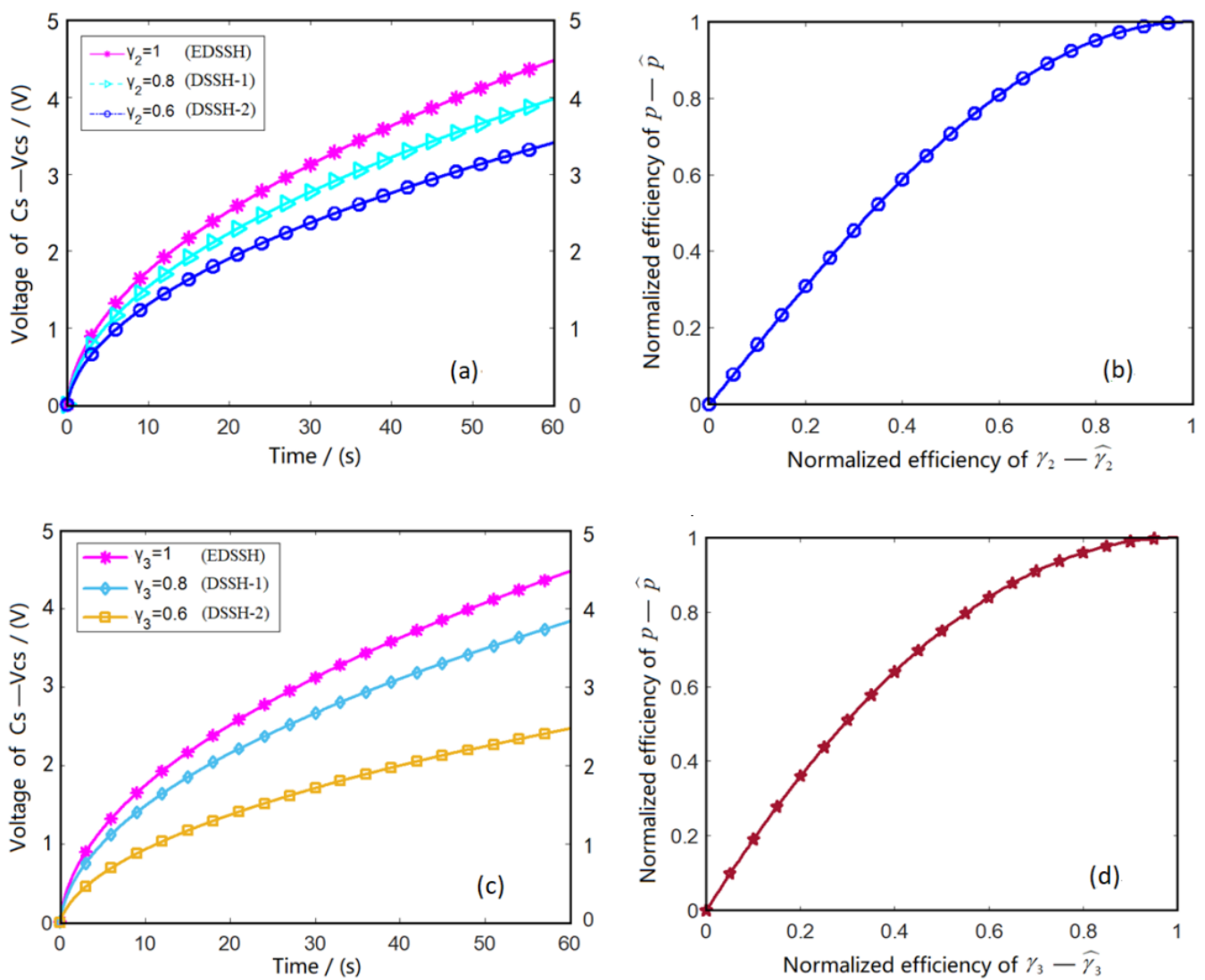

Figure 12. Comparison of charging performance of the two circuits. (a) Influence of $D_{5}$ on the charging voltage $V_{C S}$ of two circuits. (b) Influence of normalized efficiency of $L_{1}-C_{i}$ loop on normalized power. (c) Influence of $\mathrm{D}_{6}$ on the charging voltage $V_{C_{S}}$ of two circuits. (d) Influence of normalized efficiency of $\mathrm{C}_{\mathrm{i}}-\mathrm{L}_{2}$ loop on normalized power.

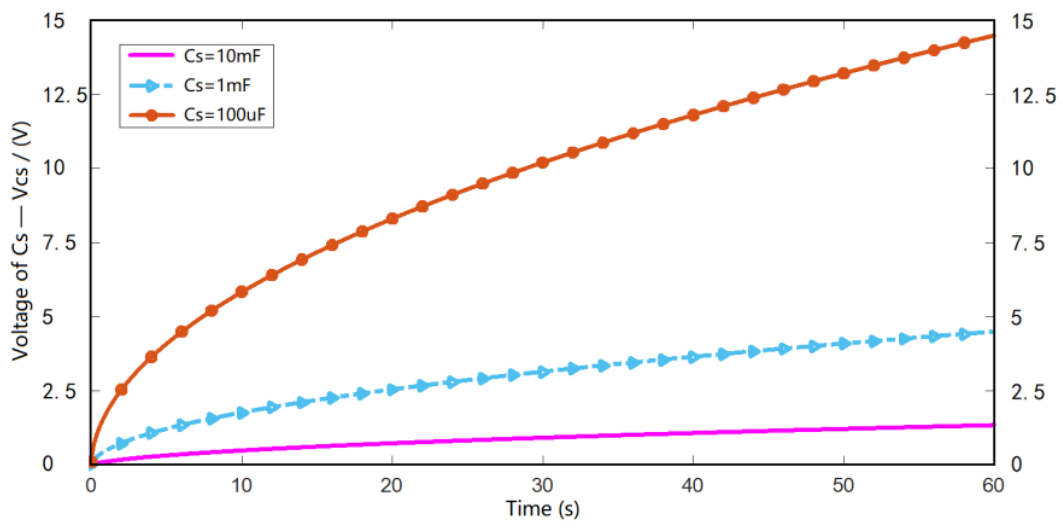

Figure 13. Influence of capacitance $C_{s}$ on $V_{C s}\left(V_{C s 0}=0\right)$.

\subsection{Design Criteria for Parameters of EDSSH Circuit}

Assuming that the piezoelectric structure resonates under the frequency of $50 \mathrm{~Hz}$ (period $T_{P}=0.02 \mathrm{~s}$ ), the longest time interval $\left(\mathrm{t}_{0}-\mathrm{t}_{3}\right)$ between two power acquisitions is half of the resonance period $\left(\frac{1}{2} T_{P}\right)$ according to Figure 5; that is to say, all the links of piezoelectric electric energy transfer to $C_{s}$ are completed in this $\frac{1}{2} T_{P}$. Since the time required for each link is related to parameters of the circuit, it is necessary to discuss the design criteria of the circuit's parameters of $C_{P}, L_{1}, C_{i}, L_{2}, C_{s}$ and control modules of $S_{1}$ which are related to power transfer efficiency. 


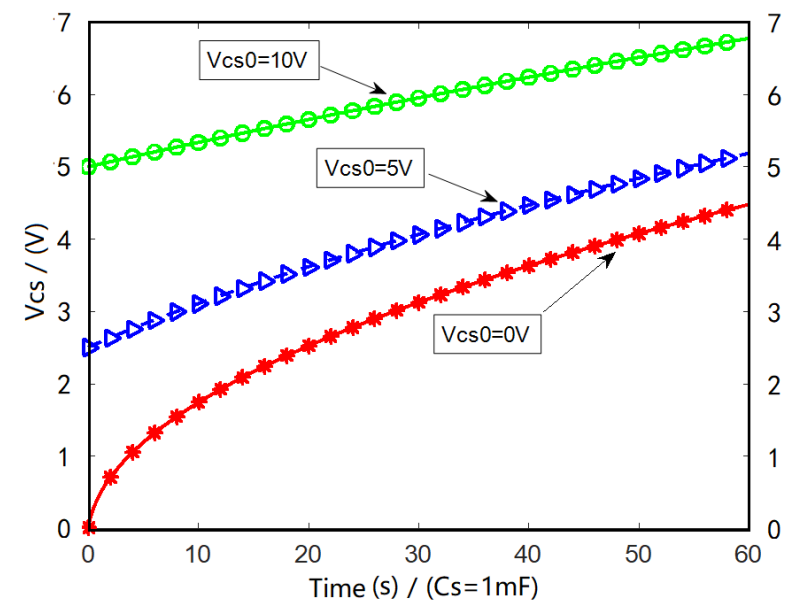

Figure 14. Influence of $V_{C s 0}$ on $V_{C s}$.

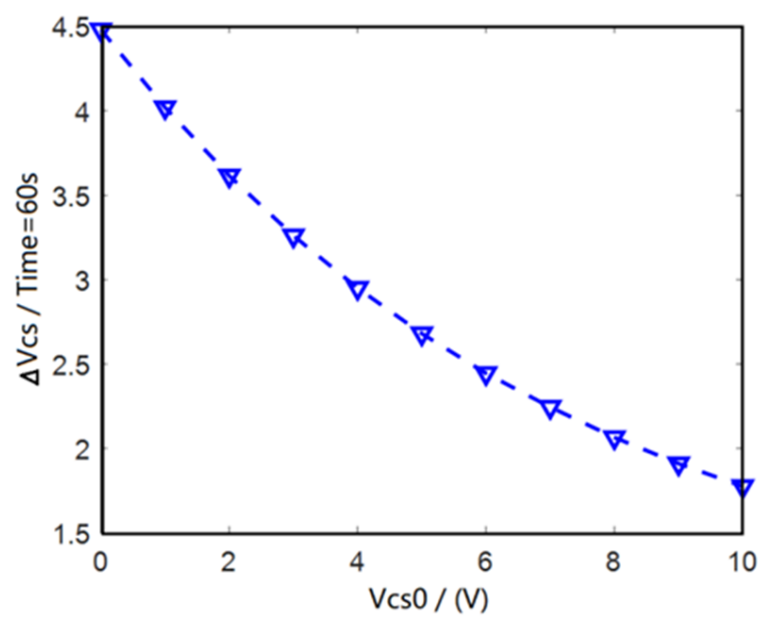

Figure 15. Influence of $V_{C s 0}$ on $\Delta V_{C s}$.

1. Design of parameters of main circuit components: First, the clamping capacitor $\left(C_{P}\right)$ of the piezoelectric structure was determined after the size design. In order to transfer the electric energy of $C_{P}$ to $L_{1}$ to the greatest extent, the time $\left(t_{0}-t_{1}\right)$ of electric energy transferred from the capacitor $\mathrm{C}_{P}$ to the inductor $\mathrm{L}_{1}$ should be controlled at one eighth of $T_{P}$; that is, the oscillation period of $C_{\mathrm{p}}-\mathrm{L}_{1}$ loop should be less than $\frac{1}{8} T_{P}$. According to the calculation formula $T=2 \pi \sqrt{C_{P} * L_{1}}<\frac{1}{8} T_{P}$ of the LC oscillation period, the design range of $L_{1}$ is $L_{1}<\frac{\left(\frac{1}{8} T_{P}\right)^{2}}{4 C_{P} \pi^{2}}$. Then, the charging capacitor was selected according to the actual needs. Since the oscillation period of the $\mathrm{L}_{2}-\mathrm{C}_{\mathrm{S}}$ loop is generally less than $\frac{1}{8} T_{P}$, it is assumed that the capacitance value of the charging capacitor is $C_{S}$, and the design range of $L_{2}$ can be determined by $L_{2}<\frac{\left(\frac{1}{8} T_{P}\right)^{2}}{4 C_{s} \pi^{2}}$. Finally, the oscillation period of the $L_{1}-C_{i}$ circuit is less than $\frac{1}{8} T_{P}$, so $C_{i}<\frac{\left(\frac{1}{8} T_{P}\right)^{2}}{4 L_{1} \pi^{2}}$. Of course, this is the basic principle and order. On the premise that the total time to complete a power transfer is less than $\frac{1}{2} T_{P}$, the time length of each circuit can be adjusted, and then the values of $L_{1}, C_{i}, L_{2}$ and $C_{S}$ can be determined.

2. Parameter design of switch control circuit of $S_{1}$ : First, the power consumption of the circuit should be as small as possible; that is to say, the resistance value of $R_{1}$ and $R_{2}$ should be as large as possible. Then the delay time $\left(T_{R C}\right)$ of the RC delay circuit composed of $C_{1}$ and $R_{2}$ should be controlled to be as short as possible, so that the power transfer can start at the amplitude of $V_{1}(t)$. The values of $R_{2}$ and $C_{1}$ were determined by $T_{R C}=R_{2} * C_{1}$. Finally, the comparator should choose the components with the lowest power consumption. 


\section{Conclusions}

(1) A low-power high-efficiency adaptive electric energy harvesting circuit for broadband PEHs is proposed. The control circuit of switches is simpler, the electronic components used is fewer, and the power loss of switch control circuits is less than that of the DSSH circuit. It is self-cold-starting with a threshold voltage as low as $0.2 \mathrm{~V}$.

(2) Compared with the DSSH circuit, the electric energy harvesting efficiency of the EDSSH circuit with the proposed RFBC is stable at the optimal value. The average charging efficiency of the EDSSH circuit is 1.51 times than that of DSSH.

(3) During the circuit test, the input voltage is an ideal sine wave signal, so the circuit can successfully capture the power extreme point of the signal. If there is noise interference in the input voltage, the circuit may operate incorrectly when capturing the power extreme point, which affects the power extraction efficiency of the circuit. Therefore, it is necessary to add circuit modules at the input of the circuit to remove noise interference.

(4) According to the electric energy conversion time of each circuit of the circuit and the charging time of $C_{S}$, it can be calculated that the frequency range of the input voltage signal that the circuit can match is $1-312.5 \mathrm{~Hz}$ To broaden the frequency range of the input signal that the circuit can match, the relevant components must be recalculated and replaced.

(5) The performance of the circuit matching nonlinear piezoelectric vibration energy harvester needs to be further investigated.

Author Contributions: A.Z. was the supervisor providing funding and administrating the project; wrote, reviewed and edited the manuscript and carried out the investigation, methodology, analysis, and validation. X.H. made great contributions to the application of MATLAB in simulation. Z.L. helped to test the parameters and also helped to perform some verification experiments. All authors have read and agreed to the published version of the manuscript.

Funding: This research was funded by Guangxi Natural Science Foundation Program 2018JJA160218, the National Natural Science Foundation of China under grants 51965014, 51765014.

Conflicts of Interest: The authors declare no conflict of interest.

\section{References}

1. Whelan, M.; Salas Zamudio, N.; Kernicky, T. Structural identification of a tied arch bridge using parallel genetic algorithms and ambient vibration monitoring with a wireless sensor network. J. Civ. Struct. Health Monit. 2018, 8, 1-16. [CrossRef]

2. Muduli, L.; Mishra, D.P.; Jana, P. Application of wireless sensor network for environmental monitoring in underground coal mines: A systematic review. J. Netw. Comput. Appl. 2018, 106, 48-67. [CrossRef]

3. Trasviña Moreno, C.; Blasco, R.; Marco, Á.; Casas, R.; Trasviña-Castro, A. Unmanned aerial vehicle based wireless sensor network for marine-coastal environment monitoring. Sensors 2017, 17, 460. [CrossRef]

4. Peng, X.; Wen, Y.; Li, P.; Yang, A.; Bai, X. A wideband acoustic energy harvester using a three degree-of-freedom architecture. Appl. Phys. Lett. 2013, 103, 164106. [CrossRef]

5. Selvan, K.V.; Ali, M.M. Micro-scale energy harvesting devices: Review of methodological performances in the last decade. Renew. Sustain. Energy Rev. 2016, 54, 1035-1047. [CrossRef]

6. Elahi, H.; Eugeni, M.; Gaudenzi, P. A review on mechanisms for piezoelectric-based energy harvesters. Energies 2018, 11, 1850. [CrossRef]

7. Safaei, M.; Sodano, H.A.; Anton, S.R. A review of energy harvesting using piezoelectric materials: State-of-the-art a decade later (2008-2018). Smart Mater. Struct. 2019, 28, 113001. [CrossRef]

8. Erturk, A.; Inman, D.J. A distributed parameter electromechanical model for cantilevered piezoelectric energy harvesters. J. Vib. Acoust. 2008, 130, 1257-1261. [CrossRef]

9. Erturk, A.; Inman, D.J. Issues in mathematical modeling of piezoelectric energy harvesters. Smart Mater. Struct. 2008, 17, 065016. [CrossRef]

10. Liao, Y.; Sodano, H.A. Model of a single mode energy harvester and properties for optimal power generation. Smart Mater. Struct. 2008, 17, 065026. [CrossRef]

11. Liao, Y.; Sodano, H.A. Optimal parameters and power characteristics of piezoelectric energy harvesters with an RC circuit. Smart Mater. Struct. 2009, 18, 045011. [CrossRef] 
12. Fakharian, O.; Salmani, H.; Kordkheili, S. A lumped parameter model for exponentially tapered piezoelectric beam in transverse vibration. J. Mech. Sci. Technol. 2019, 33, 2043-2048. [CrossRef]

13. Kärki, S.; Lekkala, J. A lumped-parameter transducer model for piezoelectric and ferroelectret polymers. Measurement 2012, 45, 453-458. [CrossRef]

14. Baishya, S.; Borthakur, D.; Kashyap, R.; Chatterjee, A. A high precision lumped parameter model for piezoelectric energy harvesters. IEEE Sens. J. 2017, 17, 8350-8355. [CrossRef]

15. Wang, G.Q.; Lu, Y.M. An improved lumped parameter model for a piezoelectric energy harvester in transverse vibration. Shock. Vib. 2014, 2014 Pt 1, 1-12. [CrossRef]

16. Sriramdas, R.; Pratap, R. An experimentally validated lumped circuit model for piezoelectric and electrodynamic hybrid harvesters. IEEE Sens. J. 2018, 18, 2377-2384. [CrossRef]

17. Ruderman, M.; Kamiya, Y.; Iwasaki, M. Extended lumped parameter electromechanical model of piezoelectric actuators. In Proceedings of the 2015 IEEE International Conference on Mechatronics (ICM), Nagoya, Japan, 6-8 March 2015 ; pp. $290-295$.

18. Elvin, N.G.; Elvin, A.A. A general equivalent circuit model for piezoelectric generators. J. Intell. Mater. Syst. Struct. 2019, 20, 3-9. [CrossRef]

19. Elvin, N.G.; Elvin, A.A. A coupled finite element-circuit Simulation model for analyzing piezoelectric energy generator. J. Intell. Mater. Syst. Struct. 2009, 20, 587-595. [CrossRef]

20. Roundy, S.; Leland, E.S.; Baker, J.; Carleton, E.; Reilly, E.; Lai, E.; Otis, B.; Rabaey, J.M.; Wright, P.K.; Sundararajan, V. Improving power output for vibration-based energy scavengers. IEEE Pervasive Comput. 2005, 4, 28-36. [CrossRef]

21. Yang, Y.; Tang, L. Equivalent circuit modeling of piezoelectric energy harvesters. J. Intell. Mater. Syst. Struct. 2009, 20, $2223-2235$. [CrossRef]

22. Wang, G.; Chen, G.; Bai, F. modeling and identification of asymmetric Bouc-Wen hysteresis for piezoelectric actuator via a novel differential evolution algorithm. Sens. Actuators A Phys. 2015, 235, 105-118. [CrossRef]

23. Zhang, J.; Xia, P. An improved PSO algorithm for parameter identification of nonlinear dynamic hysteretic models. J. Sound Vib. 2017, 389, 153-167. [CrossRef]

24. Ko, Y.R.; Hwang, Y.; Chae, M.; Kim, T.H. Direct identification of generalized Prandtl-Ishlinskii model inversion for asymmetric hysteresis compensation. ISA Trans. 2017, 70, 209-218. [CrossRef]

25. Saleem, A.; Al-Ratrout, S.; Mesbah, M. A fitness function for parameters identification of Bouc-Wen hysteresis model for piezoelectric actuators. In Proceedings of the International Conference on Electrical and Electronic Engineering (ICEEE), Istanbul, Turkey, 3-5 May 2018; pp. 119-123.

26. Noël, J.P.; Esfahani, A.F.; Kerschen, G.; Schoukens, J. A nonlinear state-space approach to hysteresis identification. Mech. Syst. Signal Process. 2017, 84, 171-184. [CrossRef]

27. He, C.; Zhi, W.; Liu, X. Magnetic property parameter identification of steel pole based on GA-PSO hybrid algorithm. Chin. J. Sci. Instrum. 2017, 38, 838-843.

28. Wang, R.; Zhang, X. Parameters optimization and experiment of a planar parallel 3-dof nanopositioning system. IEEE Trans. Ind. Electron. 2018, 65, 2388-2397. [CrossRef]

29. Xie, S.L.; Liu, H.T.; Mei, J.P.; Gu, G.Y. Modeling and compensation of asymmetric hysteresis for pneumatic artificial muscles with a modified generalized Prandtl-Ishlinskii model. Mechatronics 2018, 52, 49-57. [CrossRef]

30. Billings, S.A. Nonlinear System Identification: NARMAX Methods in the Time, Frequency, and Spatio-Temporal Domains; John Wiley \& Sons: Hoboken, NJ, USA, 2013.

31. Eichhorn, C.; Goldschmidtboeing, F.; Woias, P. Bidirectional frequency tuning of a piezoelectric energy converter based on a cantilever beam. J. Micromech. Microeng. 2009, 19, 1693-1696. [CrossRef]

32. Li, W.G.; He, S.; Yu, S. Improving power density of a cantilever piezoelectric power harvester through a curved L-Shaped proof mass. IEEE Trans. Ind. Electron. 2010, 57, 868-876. [CrossRef]

33. Shen, D.; Park, J.H.; Ajitsaria, J. The design, fabrication and evaluation of a MEMS PZT cantilever with an integrated Si proof mass for vibration energy harvesting. J. Micromech. Microeng. 2008, 18, 055017. [CrossRef]

34. Morris, D.J.; Youngsman, J.M.; Anderson, M.J. A resonant frequency tunable, extensional mode piezoelectric vibration harvesting mechanism. Smart Mater. Struct. 2008, 17, 065021. [CrossRef]

35. Guan, Q.C.; Ju, B.; Xu, J.W.; Liu, Y.B.; Feng, Z.H. Improved strain distribution of cantilever piezoelectric energy harvesting devices using H-shaped proof masses. J. Intell. Mater. Syst. Struct. 2013, 24, 1059-1066. [CrossRef]

36. Huang, D.; Zhou, S.; Litak, G. Theoretical analysis of multi-stable energy harvesters with high-order stiffness terms. Commun. Nonlinear Sci. Numer. Simul. 2019, 69, 270-286. [CrossRef]

37. Yuan, T.C.; Yang, J.; Chen, L.Q. A harmonic balance approach with alternating frequency/time domain progress for piezoelectric mechanical systems. Mech. Syst. Signal Process. 2019, 120, 274-289. [CrossRef]

38. Wang, C.; Zhang, Q.; Wang, W. Low-frequency wideband vibration energy harvesting by using frequency up-conversion and quin-stable nonlinearity. J. Sound Vib. 2017, 399, 169-181. [CrossRef]

39. Fan, K.; Tan, Q.; Liu, H. Improved energy harvesting from low-frequency small vibrations through a monostable piezoelectric energy harvester. Mech. Syst. Signal Process. 2019, 117, 594-608. [CrossRef]

40. Nabavi, S.; Zhang, L. Nonlinear multi-mode wideband piezoelectric MEMS vibration energy harvester. IEEE Sens. J. 2019, 19, 4837-4848. [CrossRef] 
41. Wang, Y.J.; Chuang, T.Y.; Lee, C. Resonant frequency self-tunable piezoelectric cantilevers for energy harvesting and disturbing torque absorbing. Sens. Actuators A Phys. 2019, 285, 25-34. [CrossRef]

42. Wang, J.; Zhou, S.; Zhang, Z. High-performance piezoelectric wind energy harvester with Y-shaped attachments. Energy Convers. Manag. 2018, 181, 645-652. [CrossRef]

43. $\mathrm{Wu}, \mathrm{Z} . ; \mathrm{Xu}, \mathrm{Q}$. Design and testing of a novel bidirectional energy harvester with single piezoelectric stack. Mech. Syst. Signal Process. 2019, 122, 139-151. [CrossRef]

44. Hu, Y.; Yong, X. A wideband vibration energy harvester based on a folded asymmetric gapped cantilever. Appl. Phys. Lett. 2014, 104, 329. [CrossRef]

45. Gael, S.; Hiroki, K.; Daniel, G.; Benjamin, D. Experimental duffing oscillator for broadband piezoelectric energy harvesting. Smart Mater. Struct. 2011, 20, 102001.

46. Kim, I.H.; Jung, H.J.; Bo, M.L. Broadband energy-harvesting using a two degree-of-freedom vibrating body. Appl. Phys. Lett. 2011, 98, 987. [CrossRef]

47. Abdelkefi, A.; Najar, F.; Nayfeh, A.H. An energy harvester using piezoelectric cantilever beams undergoing coupled bendingtorsion vibrations. Smart Mater. Struct. 2011, 20, 115007. [CrossRef]

48. Hajati, A.; Kim, S.G. Ultra-wide bandwidth piezoelectric energy harvesting. Appl. Phys. Lett. 2011, 99, 175-252. [CrossRef]

49. Karami, M.A.; Inman, D.J. Parametric study of zigzag microstructure for vibrational energy harvesting. J. Microelectromechan. Syst. 2012, 21, 145-160. [CrossRef]

50. Fan, K.; Chang, J.; Pedrycz, W. A nonlinear piezoelectric energy harvester for various mechanical motions. Appl. Phys. Lett. 2015, 106, 094102. [CrossRef]

51. Hu, H.; Dai, L.; Chen, H.; Jiang, S.; Wang, H.; Laude, V. Two methods to broaden the bandwidth of a nonlinear piezoelectric bimorph power harvester. J. Vib. Acoust. 2017, 139, 031008. [CrossRef]

52. Rui, X.; Li, Y.; Liu, Y. Experimental study and parameter optimization of a magnetic coupled piezoelectric energy harvester. Appl. Sci. 2018, 8, 2609. [CrossRef]

53. Bo, Z.; Yu, J.; Elmaimouni, L. Magneto-electric effect on guided waves in functionally graded piezoelectric-piezomagnetic fan-shaped cylindrical structures. Materials 2018, 11, 2174.

54. Dong, W.; Shilong, S.; Tse, P.W. A general sequential Monte Carlo method based optimal wavelet filter: A Bayesian approach for extracting bearing fault features. Mech. Syst. Signal Process. 2015, 52-53, 293-308.

55. Alcala-Jimenez, L.R.; Jensen, T.P.; Lei, A. Increased mechanical robustness of piezoelectric magnetoelastic vibrational energy harvesters-ScienceDirect. Microelectron. Eng. 2019, 207, 19-26. [CrossRef]

56. Valerio, A.; Carmine, S.C.; Daniele, D.; Damiano, L.; Ciro, V. Magneto-mechanical optimization and analysis of a magnetostrictive cantilever beam for energy harvesting-ScienceDirect. J. Magn. Magn. Mater. 2019, 475, 401-407.

57. Zhao, L.; Conlon, S.C.; Semperlotti, F. Broadband energy harvesting using acoustic black hole structural tailoring. Smart Mater. Struct. 2014, 23, 065021. [CrossRef]

58. Leadenham, S.; Erturk, A. Nonlinear M-shaped broadband piezoelectric energy harvester for very low base accelerations: Primary and secondary resonances. Smart Mater. Struct. 2015, 24, 055021. [CrossRef]

59. Harne, R.L.; Sun, A.; Wang, K.W. Leveraging nonlinear saturation-based phenomena in an L-shaped vibration energy harvesting system. J. Sound Vib. 2015, 363, 517-531. [CrossRef]

60. Qin, Y.; Wei, T.; Zhao, Y. Simulation and experiment on bridge-shaped nonlinear piezoelectric vibration energy harvester. Smart Mater. Struct. 2018, 28, 045015. [CrossRef]

61. Shi, G.; Xia, Y.; Wang, X.; Qian, L.; Ye, Y.; Li, Q. An efficient self-powered piezoelectric energy harvesting CMOS interface circuit based on synchronous charge extraction technique. Circuits Syst. I Regul. Pap. IEEE Trans. 2018, 65, 804-817. [CrossRef]

62. Shaikh, F.; Zeadally, S. Energy harvesting in wireless sensor networks: A comprehensive review. Renew. Sust. Energ. Rev. 2016, 55, 1041-1054. [CrossRef]

63. Lefeuvre, E.; Audigier, D.; Richard, C.; Guyomar, D. Buck-boost converter for sensorless power optimization of piezoelectric energy harvester. IEEE Trans. Power Electron. 2007, 22, 2018-2025. [CrossRef]

64. Garbuio, L.; Lallart, M.; Guyomar, D.; Richard, C. Mechanical energy harvester with ultralow threshold rectification based on SSHI nonlinear technique. IEEE Trans. Ind. Electron. 2009, 56, 1048-1056. [CrossRef]

65. Guyomar, D.; Jayet, Y.; Petit, L.; Lefeuvre, E.; Richard, C.; Lallart, M. Synchronized switch harvesting applied to self powered smart systems: Piezoactive microgenerators for autonomous wireless transmitters. Sens. Actuators A Phys. 2007, 138, 151-160. [CrossRef]

66. Guyomar, D.; Badel, A.; Lefeuvre, E.; Richard, C. Towards energy harvesting using active materials and conversion improvement by nonlinear processing. Ultrason. Ferroelectr. Freq. Control IEEE Trans. 2005, 52, 584-595. [CrossRef]

67. Liang, J.; Liao, W.H. Impedance modeling and analysis for piezoelectric energy harvesting systems. IEEE/ASME Trans. Mechatron. 2012, 17, 1145-1157. [CrossRef]

68. Badel, A.; Guyomar, D.; Lefeuvre, E.; Richard, C. Piezoelectric energy harvesting using a synchronized Switch technique. J. Intell. Mater. Syst. Struct. 2006, 17, 831-839. [CrossRef]

69. Shu, Y.; Lien, L.; Wu, W. An improved analysis of the SSHI interface in piezoelectric energy harvesting. Smart Mater. Struct. 2007, 16, 2253-2264. [CrossRef] 
70. Ramadass, Y.K.; Chandrakasan, A.P. An Efficient Piezoelectric Energy Harvesting Interface Circuit Using a Bias-Flip Rectifier and Shared Inductor. IEEE J. Solid-State Circuits 2010, 45, 189-204. [CrossRef]

71. Lefeuvre, E.; Badel, A.; Richard, C.; Petit, L.; Guyomar, D. A comparison between several vibration-powered piezoelectric generators for standalone systems. Sens. Actuators A-Phys. 2006, 126, 405-416. [CrossRef]

72. Lallart, M.; Garbuio, L.; Petit, L.; Richard, C.; Guyomar, D. Double synchronized switch harvesting (DSSH): A new energy harvesting scheme for efficient energy extraction. IEEE Trans. Ultrason. Ferroelectr. Freq. Control 2008, 55, 2119-2130. [CrossRef]

73. Lefeuvre, E.; Risquez, S.; Wei, J.; Woytasik, M.; Parrain, F. Self-Biased Inductor-Less Interface Circuit for Electret-Free Electrostatic Energy Harvesters. J. Phys. Conf. Ser. Power MEMS 2014, 557, 012052. [CrossRef]

74. Gasnier, P.; Willemin, J.; Boisseau, S.; Despesse, G.; Condemine, C.; Gouvernet, G.; Chaillout, J.-J. An autonomous piezoelectric energy harvesting IC based on a synchronous multi-Shot technique. IEEE J. Solid-State Circuits 2014, 49, 1561-1570. [CrossRef]

75. Dini, M.; Romani, A.; Filippi, M.; Tartagni, M. A nanopower synchronous charge extractor IC for low-voltage piezoelectric energy harvesting with residual charge inversion. IEEE Trans. Power Electron. 2016, 31, 1263-1274. [CrossRef]

76. Yeatman, E.M.; Ahmadian, M.; Ghasemi-Nejhad, M.N. Energy harvesting: Small scale energy production from ambient sources. Int. Soc. Opt. Photonics 2009, 7288, 728802.

77. Shen, H.; Qiu, J.H.; Ji, H.L. Enhanced synchronized switch harvesting (ESSH): A new energy harvesting scheme for efficient energy extraction. Smart Mater. Struct. 2010, 19, 115017. [CrossRef]

78. Lefeuvre, E.; Badel, A.; Richard, C.; Guyomar, D. Piezoelectric energy harvesting device optimization by synchronous electric charge extraction. J. Intell. Mater. Syst. Struct. 2005, 16, 865-876. [CrossRef]

79. Wang, G.; Li, P.; Wen, L.; Ji, X. Self-powered ultra-low-power low-threshold synchronous circuit for weak piezoelectric energy harvesting. Sens. Actuators A-Phys. 2021, 322, 112632. [CrossRef]

80. Wu, L.; Zhu, P.; Xie, M. A Self-powered hybrid SSHI circuit with a wide operation range for piezoelectric energy harvesting. Sensors 2021, 21, 615. [CrossRef] [PubMed]

81. Din, A.U.; Kamran, M.; Mahmood, W.; Aurangzeb, K.; Lee, J.W. An efficient CMOS dual switch rectifier for piezoelectric energy-harvesting circuits. Electronics 2019, 8, 66. [CrossRef]

82. Chen, N.; Wei, T.; Jung, H.J.; Lee, S. Quick self-start and minimum power-loss management circuit for impact-type micro wind piezoelectric energy harvesters. Sens. Actuators A-Phys. 2017, 263, 23-29. [CrossRef]

83. Lallart, M. Nonlinear technique and self-powered circuit for efficient piezoelectric energy harvesting under unloaded cases. Energy Convers. Manag. 2016, 133, 444-457. [CrossRef]

84. Zhang, Z.; Xiang, H.; Tang, L. Modeling analysis and comparison of four charging interface circuits for piezoelectric energy harvesting. Mech. Syst. Signal Process. 2021, 152, 107476. [CrossRef]

85. Tang, L.H.; Yang, Y.W. Analysis of synchronized charge extraction for piezoelectric energy harvesting. Smart Mater. Struct. 2011, 20, 085022. [CrossRef] 